\title{
Stratospheric and mesospheric temperature variations for the quasi-biennial and semiannual (QBO and SAO) oscillations based on measurements from SABER (TIMED) and MLS (UARS)
}

\author{
F. T. Huang ${ }^{1}$, H. G. Mayr ${ }^{2}$, C. A. Reber ${ }^{2}$, J. M. Russell ${ }^{3}$, M Mlynczak ${ }^{4}$, and J. G. Mengel ${ }^{5}$ \\ ${ }^{1}$ Creative Computing Solutions Inc., Rockville, MD 20850, USA \\ ${ }^{2}$ NASA Goddard Space Flight Center, Greenbelt MD, 20771, USA \\ ${ }^{3}$ Hampton University, Center for Atmospheric Sciences, Hampton, VA, 23668, USA \\ ${ }^{4}$ NASA Langley Research Center, Hampton, VA, 23681, USA \\ ${ }^{5}$ Science Systems and Applications, Lanham, MD, 20706, USA
}

Received: 28 February 2006 - Revised: 5 July 2006 - Accepted: 17 July 2006 - Published: 13 September 2006

\begin{abstract}
We present the zonal mean temperature variations for the quasi-biennial oscillation (QBO) and the semiannual oscillation (SAO) based on data from SABER on the TIMED spacecraft (years 2002 to 2004) and from MLS on the UARS mission (1992 to 1994). The SABER measurements provide the rare opportunity to analyze data from one instrument over a wide altitude range (15 to $95 \mathrm{~km})$, while MLS data were taken in the 16 to $55 \mathrm{~km}$ altitude range a decade earlier. The results are presented for latitudes from $48^{\circ} \mathrm{S}$ to $48^{\circ} \mathrm{N}$. New results are obtained for the QBO, especially in the upper stratosphere and mesosphere, and at mid-latitudes. At Equatorial latitudes, the QBO amplitudes show local peaks, albeit small, that occur at different altitudes. From about 20 to $40 \mathrm{~km}$, and within about $15^{\circ}$ of the Equator, the amplitudes can approach $3.5^{\circ} \mathrm{K}$ for the stratospheric QBO (SQBO). For the mesospheric QBO (MQBO), we find peaks near $70 \mathrm{~km}$, with temperature amplitudes reaching $3.5^{\circ} \mathrm{K}$, and near $85 \mathrm{~km}$, the amplitudes approach $2.5^{\circ} \mathrm{K}$. Morphologically, the amplitude and phase variations derived from the SABER and MLS measurements are in qualitative agreement. As a function of latitude, the QBO amplitudes tend to peak at the Equator but then increase again pole-ward of about $15^{\circ}$ to $20^{\circ}$. The phase progression with altitude varies more gradually at the Equator than at mid-latitudes. Many of the SAO results presented are also new, in part because measurements were not previously available or were more limited in nature. At lower altitudes near $45 \mathrm{~km}$, within about $15^{\circ}$ of the Equator, the temperature amplitudes for the stratospheric SAO (SSAO) reveal a local maximum of about $5^{\circ} \mathrm{K}$. At higher altitudes close to the Equator, our results show separate peaks of about $7^{\circ} \mathrm{K}$ near 75 and $90 \mathrm{~km}$ for the mesospheric SAO (MSAO). In the SAO results, significant inter-annual differences are evident, with the amplitudes being largest in 2002 relative to 2003 and 2004. As in the case
\end{abstract}

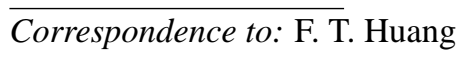

(fthuang@comcast.net) for the QBO, the SAO temperature amplitudes go through minima away from the Equator, and then increase towards mid latitudes, especially at altitudes above $55 \mathrm{~km}$. We compare our findings with previously published empirical results, and with corresponding results from the numerical spectral model (NSM). Although not a focus of this study, we also show results for the inter-annual variations (which appear to be generated at least in part by the QBO) of the migrating diurnal tide. In the upper mesosphere, their amplitudes can approach $20^{\circ} \mathrm{K}$, and they are derived jointly with the zonalmean components.

Keywords. Meteorology and atmospheric dynamics (Middle atmosphere dynamics; Thermospheric dynamics) - Atmospheric composition and structure (Pressure, density, and temperature)

\section{Introduction}

The zonal-mean temperature variations of the Semi-annual Oscillation (SAO) and Quasi-biennial Oscillation (QBO) in the stratosphere and mesosphere are produced mainly by dynamical processes, which are associated with the zonal circulation that dominates at, and is confined to equatorial latitudes. In this respect, the dynamical situation is similar to the one that controls the temperature variations of the dominant Annual Oscillation (AO) in the mesosphere at high latitudes (Lindzen, 1981), in contrast to the stratospheric AO, which is generated primarily by solar heating.

At low latitudes, the zonal mean zonal winds of the SAO peak in the upper stratosphere near $50 \mathrm{~km}$ with velocities of about $30 \mathrm{~m} / \mathrm{s}$, eastward during equinox and westward around solstice (e.g., Hirota, 1980). In the upper mesosphere near $80 \mathrm{~km}$, a second peak is observed with comparable magnitude but opposite phase.

Published by Copernicus GmbH on behalf of the European Geosciences Union. 
The zonal mean zonal wind QBO is observed in the lower stratosphere with a maximum at around $30 \mathrm{~km}$, having amplitudes close to $20 \mathrm{~m} / \mathrm{s}$ (e.g., Reed, 1965, 1966). Such oscillations, with opposite phases, have been inferred also for the upper mesosphere (Burrage et al., 1996) based on measurements with the HRDI instrument on UARS (Hays et al., 1993).

Lindzen and Holton (1968) and Holton and Lindzen (1972) established that wave-mean flow interactions can generate a QBO. They invoked equatorially trapped planetary waves (i.e., eastward propagating Kelvin waves and westward propagating Rossby gravity waves) to provide the wave forcing through critical level absorption and radiative damping. Plumb (1977), Plumb and Bell (1982) and Dunkerton (1985a), and others, further elucidated the properties of this mechanism. With the Sun crossing the equator twice a year, a semi-annual oscillation is generated through momentum advection from the summer to the winter hemisphere. The magnitude of this oscillation is small compared with observations (e.g., Meyer, 1970; Hamilton, 1986), and the theory for the QBO by Lindzen and Holton was therefore extended to also explain the SAO in the stratosphere (e.g., Dunkerton, 1979; Hamilton, 1986, Hitchman and Leovy, 1986). The planetary waves that are postulated to drive the equatorial oscillations in the stratosphere are largely dissipated there, and therefore cannot significantly affect the dynamics of the upper mesosphere. Lindzen (1981) had shown that in this region of the atmosphere, at higher altitudes, small-scale gravity waves (GW) can cause the seasonal variations of the zonal circulation to reverse; and Dunkerton (1982a) proposed this mechanism to explain the observed SAO above $70 \mathrm{~km}$. Hitchman and Leovy (1986) provide a good discussion of the dynamical processes that generate the SAO in the stratosphere and mesosphere. They also discussed specifically the important role of the gravity-wave-driven meridional circulation.

During the last decade, the importance of GWs relative to planetary waves in the middle atmosphere has been increasingly recognized. From a modeling study, Hitchman and Leovy (1988) concluded that the observed Kelvin waves, based on data from the Limb Infrared Monitor of the Stratosphere (LIMS) instrument (Nimbus 7 satellite), can account for only $20 \%-70 \%$ of the stratospheric SAO and that GWs are likely to be important too. With a general circulation model (GCM) that resolves planetary waves but not GWs, Hamilton et al. (1995) showed that the observed eastward phase of the stratospheric SAO cannot be simulated and that the amplitude of the QBO is almost an order of magnitude smaller than observed, suggesting again that GWs are playing a more prominent role. Except for a few attempts at simulating the zonal winds of the QBO and SAO with resolved GWs (e.g., Takahashi, 1999), these waves need to be parameterized for global-scale models. Following Lindzen (1981), the parameterization of GW interactions with the background flow thus has been the subject of numerous studies (e.g., Dunkerton, 1982b, c, 1987; Fritts and Lu, 1993; Hines, 1997a, b). The Doppler Spread Parameterization (DSP) of Hines $(1997 \mathrm{a}, \mathrm{b})$ for example, which deals with a spectrum of waves and accounts both for wave-wave and wave-meanflow interactions, has been applied successfully in several models (e.g., Mengel et al., 1995; Mayr et al., 1997; Manzini et al., 1997; Akmaev, 2001; McLandress, 1998, 2002).

An important property of the QBO is that the observed confinement of the zonal winds to equatorial latitudes can be simulated even with a wave source that is globally uniform (e.g., Mengel et al., 1995). At the equator where the Coriolis force vanishes, the waves accelerate the zonal winds without generating a meridional circulation that would tend to redistribute and dissipate the flow momentum. The flow thus is essentially trapped around the equator, where the wave interaction is primarily balanced by eddy viscosity causing the QBO to propagate down. Away from the equator, irrespective of the wave source, the meridional circulation comes into play and dissipates the zonal flow (e.g., Haynes, 1998). Without the meridional circulation, the QBO zonal winds at the equator could be described for simplicity with a one dimensional "prototype model", as Lindzen and Holton (1968) had pointed out.

Holton and Tan (1980) showed how the wave-driven QBO can affect the temperature variations at high latitudes, and in several subsequent papers (e.g., Labitzke, 1982, 1987; Labitzke and van Loon, 1988, 1992) the processes involved were further explored. While the subordinate role of the meridional circulation near the equator explains the essential properties of the zonal winds that characterize the QBO, and the $\mathrm{SAO}$ to a lesser extent, the dynamical situation is virtually reversed for the related temperature variations. The meridional circulation that dissipates the QBO zonal winds away from the equator produce temperature oscillations that extend to high latitudes, and in the mesosphere in particular, as shown in 2-D models (e.g., Mayr et al., 2000). Temperature observations thus can provide valuable information bearing on the configuration of the meridional circulation, which in turn depends on the latitude dependence of the wave forcing that generates the QBO and SAO.

In the following, we present results from an analysis of temperature data obtained from the ThermosphereIonosphere-Mesosphere-Energetics and Dynamics (TIMED) satellite and from the Upper Atmosphere Research Satellite (UARS, Reber, 1993). The measurements were carried out on TIMED by the Sounding of the Atmosphere using Broadband Emission Radiometry (SABER) instrument (Russell et al., 1999), and on UARS by the Microwave Limb Sounder (MLS, Barath et al., 1993). The data are analyzed to derive the zonal-mean temperature variations for the $\mathrm{QBO}$ and $\mathrm{SAO}$ from 15 to $95 \mathrm{~km}$ altitude and from $48^{\circ} \mathrm{S}$ to $48^{\circ} \mathrm{N}$ latitude.

Our results are compared with those obtained from other satellites, sounding rockets, and ground-based observations. We also compare them with recent results from the Numerical Spectral Model (Mayr and Mengel, 2005). 
Within about $15^{\circ}$ of the Equator, our results for both the QBO and SAO show that there are small local peaks in amplitudes as a function of altitude. For the QBO in the mesosphere (MQBO), there are separate peaks near 70 and $85 \mathrm{~km}$. In the stratosphere (SQBO), the amplitudes are broadly larger from about 20 to $40 \mathrm{~km}$. Although the amplitudes tend to decrease away from the Equator, pole-ward of about $20^{\circ}$ latitude, the amplitudes can recover to larger values, depending on the altitude. The phase variations with altitude are quite different at low latitudes compared to those at mid-latitudes. For the equatorial SAO, there are peaks in amplitude near $45 \mathrm{~km}$, corresponding to the stratosphere semiannual oscillation (SSAO), and separate peaks near 75 and $90 \mathrm{~km}$, corresponding to the mesospheric oscillation (MSAO). As with the QBO, the SAO amplitudes tend to decrease away from the Equator, but can increase at higher latitudes, especially above about $55 \mathrm{~km}$.

Although thermal tides are not the focus of this study, their variations are embedded in the data, can be significant, and cannot be ignored. The tidal variations need to be unraveled from the mean variations in the data in order to obtain more accurate estimates of both. In addition to the zonalmean components, it is thus important that our analysis also accounts for the seasonal and inter-annual temperature variations of the diurnal tides, and we present some results for that as well.

\section{Satellite data, sampling, and analysis}

TIMED was launched at the end of 2001, and we analyzed the SABER temperature data for years 2002 through 2004, in the altitude range from 15 to $95 \mathrm{~km}$. UARS was launched in September 1991, and the MLS data were analyzed for 1992 and 1993, from 100 to $1 \mathrm{hPa}$ (about 16 to $48 \mathrm{~km}$ ). The SABER and MLS instruments both measure the emitted radiation as they view the Earth's limb, and the temperatures are retrieved by applying radiative transfer analysis. The data are sampled at different latitudes because of the north/south motion of the satellites, and different longitudes are sampled due to the rotation of the Earth relative to the orbital plane. It takes up to one day to sample the data over the globe, so global measurements are not obtained simultaneously. The SABER project supplies level 2 data (version 1.4), which represent the measurements at the footprints of the instrument as a function of space and time. We interpolated the data to fixed altitude surfaces and latitudes. They were then averaged over longitude for the analysis. Our analyses are made at altitude intervals of $2.5 \mathrm{~km}$ (close to the resolution of the data) and latitude intervals of $4^{\circ}$. The analyses are made independently at individual latitudes and altitudes, and are uncoupled from each other. MLS provides level 3 data at regular latitudes and pressure surfaces.

On any given day, irrespective of longitude, satellites usually sample the data at only two local solar times around a lat- itude circle, one for the ascending (north bound) orbit mode, and one for the descending mode. For sun-synchronous satellites, the two local times remain the same throughout the mission, making it impractical to quantitatively analyze variations as a function of local time.

Unlike sun-synchronous satellites, the orbital planes of TIMED and UARS precess slowly due to the respective orbital inclinations of $74^{\circ}$ and $57^{\circ}$. Because the orbital precession is slow, SABER and MLS also sample essentially only at one local solar time (corresponding to each orbital mode) during a given day, around a given latitude circle. Therefore, estimates of the zonal mean (average of the data around a latitude circle for a given day) can be biased by variations with local time. From day to day, for a given latitude and orbital mode, the local times of the measurements decrease by about 12 and $20 \mathrm{~min}$ for TIMED and UARS, respectively. Using both orbital modes, it takes 60 days for SABER and 36 days for MLS to sample the data over the full range of local times, thereby providing more information on variations with local time, compared to sun-synchronous satellites. However, over periods of 60 and 36 days, both the diurnal tides and the zonal-mean variations contribute to the observed temperature variations, and therefore they need to be separately identified. In the mesosphere and lower thermosphere for example, the temperature amplitudes of the diurnal tide $\left(\sim 20^{\circ} \mathrm{K}\right)$ can be as large as those of the zonal-mean variations. To account for the above properties of the data sampling, the algorithm employed in the analysis estimates jointly the diurnal variations of the diurnal tides and the zonal mean variations as described in the appendix. Applying least square analysis to the satellite data at a given altitude and latitude, the algorithm estimates the coefficients of a two-dimensional Fourier series with the independent variables being local solar time and day-of-year. For the zonal mean, the Fourier components as a function of day of year then describe the temperature variations of the $\mathrm{QBO}, \mathrm{AO}, \mathrm{SAO}$, and higher harmonics. Because of the sampling in local time described above, the analysis of data averaged over longitude produces variations with local time that correspond to migrating tides. The algorithm used here has been successfully applied previously to UARS temperature and wind data, and to SABER temperature data, as discussed in Huang et al. (2003, 2005).

As an example of our analysis, we present in Fig. 1 the SABER temperature $\left({ }^{\circ} \mathrm{K}\right)$ data averaged over longitude and the estimated results, plotted at the Equator versus day of year for years 2002 and 2003. The upper panel (a) shows the data and analysis results at $35 \mathrm{~km}$. The red and green lines show the data from the ascending and descending modes, and the diamonds and squares represent the corresponding estimated fit to the data. To avoid crowding, the fitted values are presented only for every 3 data points. The estimated fit is obtained by evaluating the Fourier series at the same day and same local time as the data. Note that the ascending and descending mode data are not very different even though they represent very different local times, reflecting the relatively 

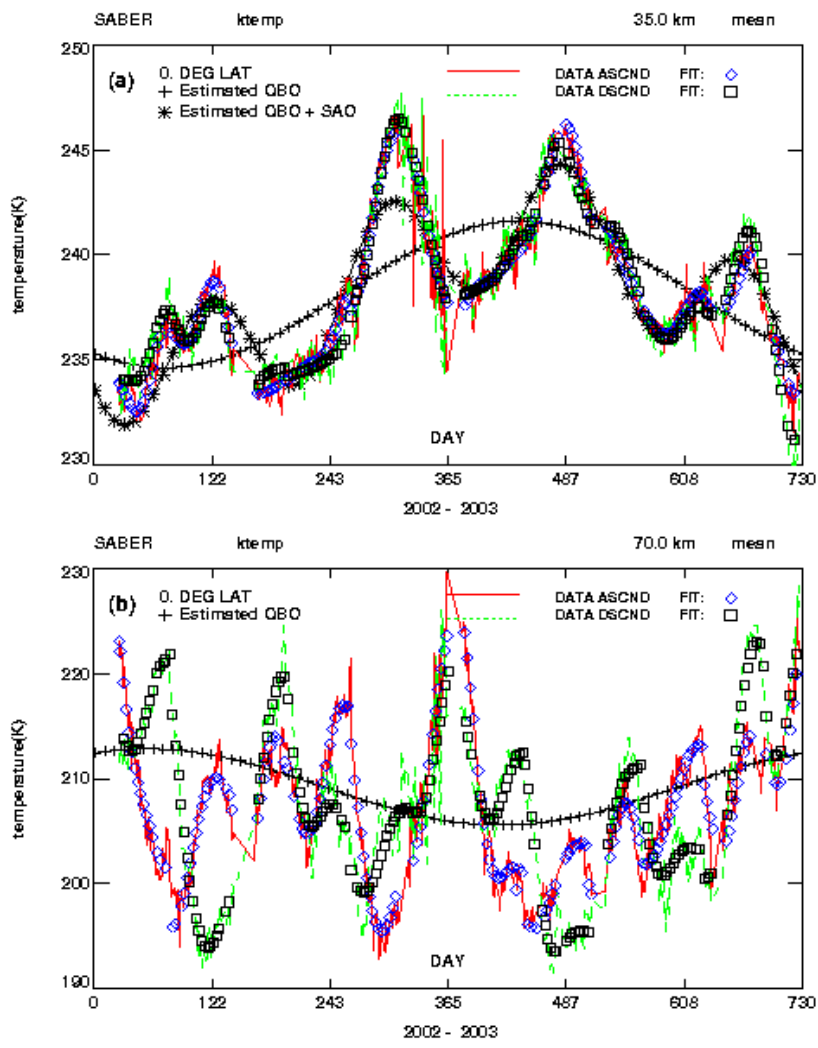

Fig. 1. Zonally (longitudinally) averaged SABER temperature data and derived (estimated) analysis results plotted versus day of years 2002-2003 at the Equator for $35 \mathrm{~km}$ (a) and $70 \mathrm{~km}$ (b). Red line and diamonds represent ascending mode data and fit, respectively. Green line and squares represent descending mode data and fit, respectively. Black “+” represent estimated QBO; black asterisks estimated QBO + SAO. To avoid crowding, only the QBO component is shown at $70 \mathrm{~km}$ where the tidal variations are large.

small tidal variations. Our analysis shows that the observed temperature variations at $35 \mathrm{~km}$ primarily reflect that of the zonal mean, rather than the tides. This is evident from the estimates for the QBO (plus yearly mean) presented with "+" symbols and from the sum of QBO and SAO (asterisks), which are derived with our algorithm.

Analogous to Fig. 1a, we present in the lower panel (b) the data and analysis results for $70 \mathrm{~km}$. At this altitude, in contrast to $35 \mathrm{~km}$, the ascending and descending mode data for each day can differ significantly, by up to $20^{\circ} \mathrm{K}$, reflecting the larger tidal variations at different local times. As the day numbers increase, the data are sampled at local times that decrease by about $12 \mathrm{~min}$ each day. Since the algorithm employs a Fourier series that describes the inter-annual, seasonal, and inter-seasonal variations (with periods as short as two months), the derived values for each day represent a relatively close fit to the data, reflecting the year-long variations of the tides and the zonal mean components. As in Fig. 1a, we show with "+" the estimated QBO component in the temperature variations derived with our algorithm, which confirms that the temperature oscillations extend with significant amplitudes into the upper mesosphere, as also observed in the zonal wind data from UARS (Burrage et al., 1996). The derived SAO component is even larger, but is not shown because the plot becomes "busy" and difficult to read.

Our analysis differs from that of Dunkerton and Delisi (1985b) who analyzed data from the NOAA Monthly Climatic Data for the World (MCDW), in which the QBO is treated as the residual after removing the annual and semiannual components from the data. This approach works well in the lower stratosphere where the tides are weak as seen from Fig. 1a. In the upper stratosphere and mesosphere however, the QBO and SAO are derived with an analysis of the kind presented here, which accounts for the large tidal oscillations embedded in the data shown in Fig. $1 b$.

\section{Measurement results}

\subsection{Zonal-mean components}

\subsubsection{Quasi-Biennial Oscillation (QBO)}

Unlike the 6-month SAO and the 12-month AO that are closely tied to solar heating, the QBO phenomenon is characterized by periods (on average somewhat larger than two years), phases, and amplitudes that are not tied to the seasonal cycle but can vary with space and time. This makes it difficult to describe the QBO in terms of Fourier series, which are characterized by fixed periods, amplitudes, and phases. We also have only three years of data, and the statistics therefore are not good.

In the analysis presented here, we estimated the QBO temperature component by assuming periods of $22,24,26,28$, and 29 months. We also used a sliding window in our analysis. For example, in addition to estimating the QBO from data in the year day interval 2002001 to 2003365 , we have also applied the algorithm to data in the interval 2003001 to 2004365, among others. The salient features of the derived QBOs are not sufficiently different to clearly choose one period over the others. Considering that the observed QBO period of the zonal winds in the lower stratosphere (where the oscillation originates) is close to 26 months we present results by assuming a period of 26 months, and for comparison we present also some results for the 24-month QBO. That 26 months may not match the period of the QBO exactly, and that the period, amplitude, and phase may drift over a cycle, is similar to the situation where the represented sinusoids are modulated, and similar to effects of applying data windows. Effectively, these can result in leakage to adjacent frequencies, and smoothing in the amplitudes (Bloomfield, 1976). However, the effects are not expected to be very significant, since the actual amplitudes and phases vary relatively slowly and smoothly. 

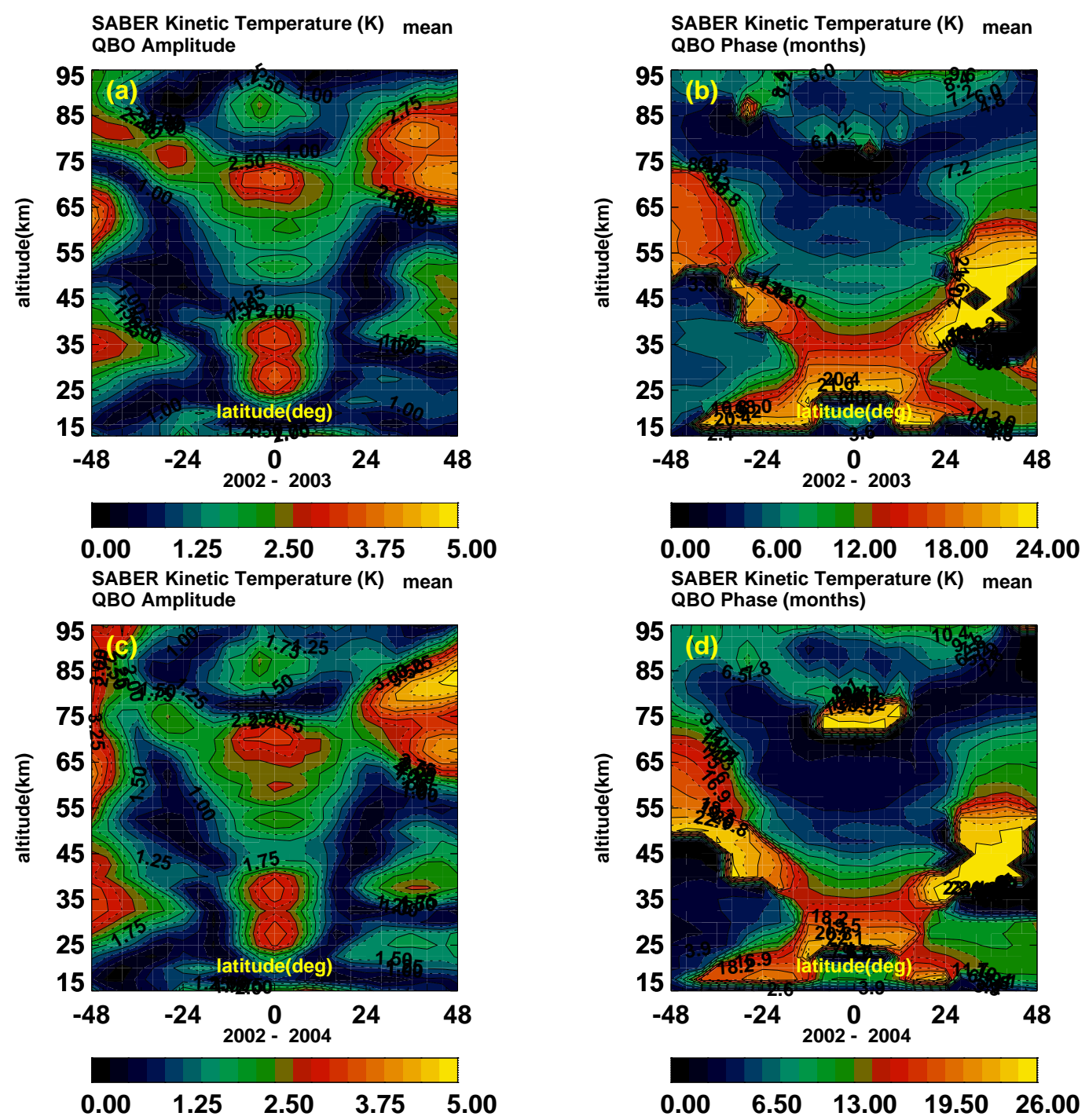

Fig. 2. Amplitude (left) and phase (right) for derived QBO temperature variations based on SABER data, plotted versus altitude (15 to $95 \mathrm{~km}$ ) and latitude $\left(48^{\circ} \mathrm{S}\right.$ to $\left.48^{\circ} \mathrm{N}\right)$. The top row (a) and (b) represents results for an assumed QBO period of 24 months obtained from year days 2002001 to 2003365. For the bottom row (c) and (d) with 26-month QBO period, the results are obtained from data from year days 2002001 to 2004060.

For an assumed 24-month periodicity, we show in the top row of Fig. 2 the derived amplitudes (a) and phases (b) based on SABER temperature data from year day 2002001 to 2003365 , plotted versus altitude (15 to $95 \mathrm{~km}$ ) and latitude $\left(48^{\circ} \mathrm{S}\right.$ to $\left.48^{\circ} \mathrm{N}\right)$. We cannot get reliable results poleward of about $48^{\circ}$ latitude since the measurements there are made only at alternate 60-day intervals. In the bottom row of Fig. 2, the corresponding results are presented for an assumed period of 26 months, based on data from year days 2002001 to 2004060 . From this it can be seen that the basic features of the derived QBO signatures for the assumed periods of 24 and 26 month are similar. The QBO amplitudes are prominent at equatorial latitudes (approaching $3.5^{\circ} \mathrm{K}$ ) and are mostly symmetric with respect to the Equator. But signif- icant amplitudes also occur at mid-latitudes where they can approach $4^{\circ} \mathrm{K}$. With assumed periods of 28 and 29 months (not shown), the difference is mainly that the local amplitude maximum near $70 \mathrm{~km}$ is diminished relative to that for 24 and 26-month periodicities. The larger maxima between 25 and $40 \mathrm{~km}$, and near $85 \mathrm{~km}$, still remain essentially unchanged.

For comparison and analogous to Fig. 2, we present in Fig. 3 the derived temperature amplitudes and phases based on measurements from the MLS instrument on UARS. Assuming a period of 26 months, the QBO signature is derived from data between 100 and $1 \mathrm{hPa}$ (about 16 and $48 \mathrm{~km}$ ) for year days 1992001 to 1994060 , about ten years before the SABER measurements (bottom row of Fig. 2). The MLS instrument does not produce data over as large an altitude 


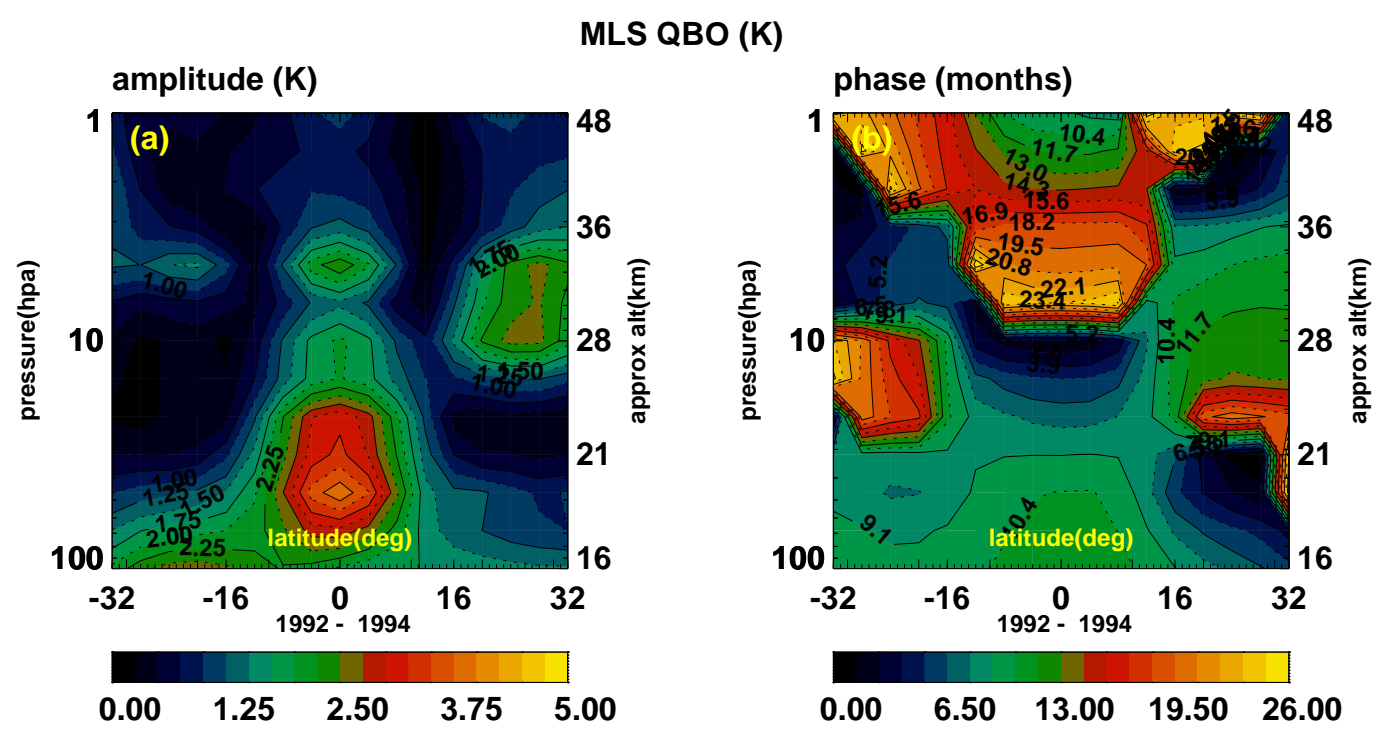

Fig. 3. Analogous to Fig. 2 but for MLS (UARS) temperature measurements. Derived amplitude (a) and phase (b) variations for a 26-month QBO based on data from year days 1992001 to 1994060, plotted on altitude versus latitude coordinates commensurate with the limited coverage on UARS.

range as SABER does, and due to the UARS orbital characteristics, we do not get results pole-ward of $32^{\circ}$ latitude. From Figs. 2 and 3, it appears that the QBO morphologies produced by the two instruments are similar, with the amplitude maxima occurring near the equator. The differences in phases between results based on SABER and on MLS data are understandable since the QBO periods are not constant. It can be seen that vertical wavelengths of about $30 \mathrm{~km}$ appear in both cases.

For comparison with other QBO results, we present with Fig. 4 the inferred SABER temperature variations themselves (rather and amplitudes and phases). In the left (a) and right (b) panels of the upper row, the temperature variations are shown for year days 2003075 (equinox) and 2002180 (solstice), which are obtained for an assumed 26-month QBO period from measurements for year days 2002001 to 2004060 . The changes in phase with altitude and latitude below $45 \mathrm{~km}$ are qualitatively consistent with results from the United Kingdom Meteorological Office (UKMO) stratospheric assimilation (Randel et al., 1999, Baldwin et al., 2001), which are based on a combination of measurements and modeling. Our results show that the vertical phase changes continue at higher altitudes (UKMO results above $45 \mathrm{~km}$ were not provided). There are also phase reversals with latitude above $45 \mathrm{~km}$, although they are less extreme above about $70 \mathrm{~km}$. The left plot (c) of the lower row is that portion of (a) between 15 and $50 \mathrm{~km}$ and $-32^{\circ}$ and $32^{\circ}$ latitude to better compare with the lower right plot (d) of Fig. 4, which is based on MLS data (year days 1992001 to 1994060) for year day 1992270, to correspond to equinox conditions. Note the small differences in plot limits between the two plots. MLS does not provide measurements over as large an altitude and latitude range as does SABER. Considering that the QBO period is variable and phase comparisons are problematic, it is reasonable to conclude that the MLS and SABER measurements and the UKMO results for the stratosphere are in qualitative agreement.

\section{Equatorial QBO}

From the SABER and MLS results in Figs. 2 and 3 respectively, it is evident that the temperature QBO amplitudes in the stratosphere reach a maximum within about $10^{\circ}$ to $15^{\circ}$ of the Equator. The peak values for this stratospheric QBO (SQBO) at altitudes from about 20 to $40 \mathrm{~km}$ approach $3.5^{\circ} \mathrm{K}$ for SABER and MLS. For the mesospheric QBO (MQBO) at the Equator, the temperature peaks from SABER are smaller and sharper, i.e., about $3^{\circ} \mathrm{K}$ near $70 \mathrm{~km}$ and $2^{\circ} \mathrm{K}$ near $85 \mathrm{~km}$. Our analysis with different QBO periods between 24 and 29 months shows that the peak near $85 \mathrm{~km}$ is more robust than that near $70 \mathrm{~km}$

The zonal winds of the QBO, which are confined to the tropics, are usually presented at latitudes near the Equator, plotted versus time and altitude. With the same format, we present with Fig. 5 in the left panel (a) the inferred QBO temperatures for a period of 24 months based on SABER data from year-days 2002001 to 2003365 , and on the right the results for a 26-month oscillation based on data from 2002001 to 2004060 . The variations are shown over two cycles to reveal the pattern more clearly. From this, it is evident that in the stratosphere below $40 \mathrm{~km}$, the QBO signature in the temperature propagates down with a velocity of about $1.3 \mathrm{~km} / \mathrm{month}$, which is in agreement with the observed zonal wind pattern. In the mesosphere, the propagation velocity is 


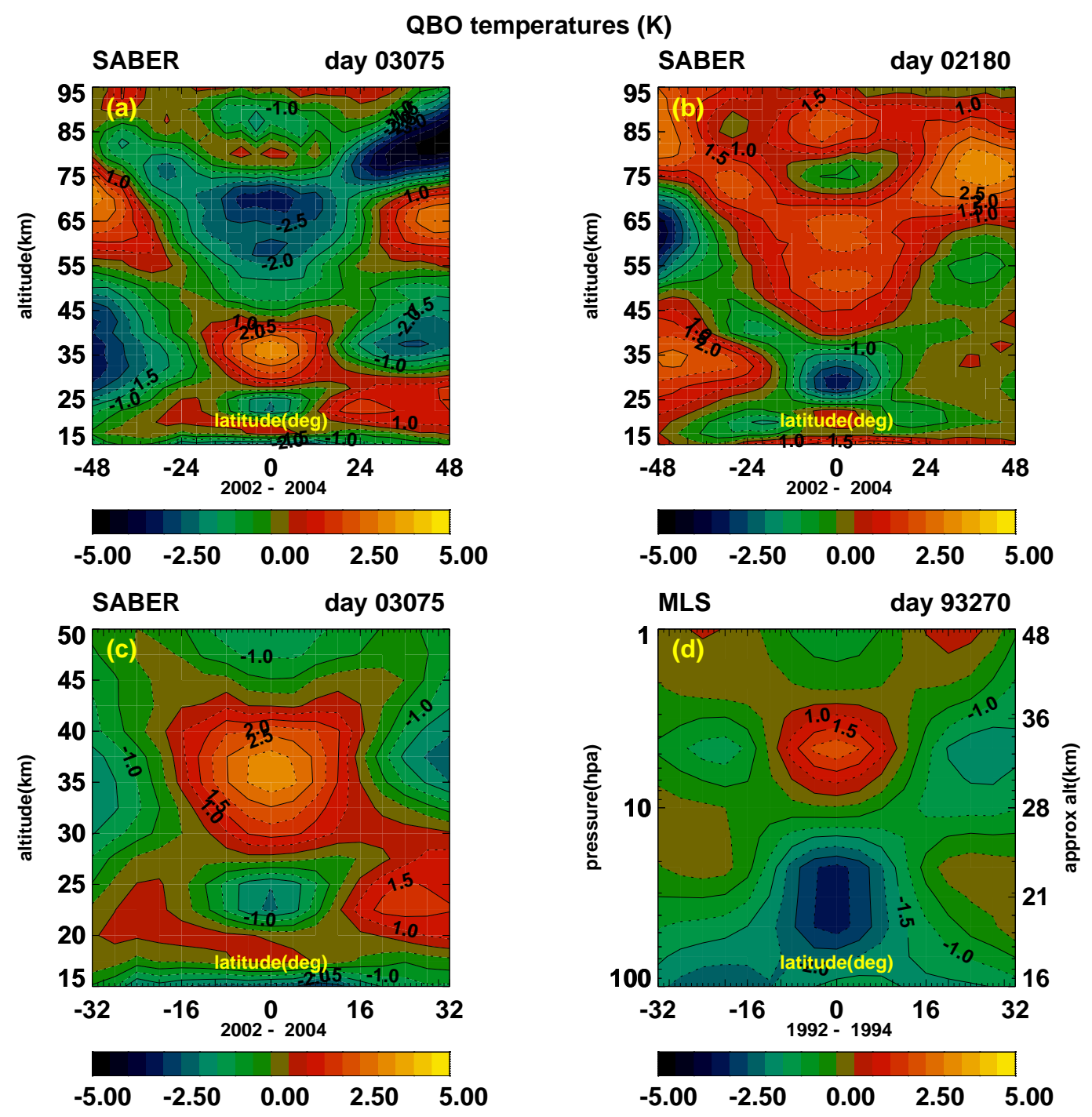

Fig. 4. Derived QBO temperature variations for selected days to illustrate the altitude-latitude morphology for 15 to $95 \mathrm{~km}$ and $48^{\circ} \mathrm{S}$ to $48^{\circ} \mathrm{N}$. Top row based on SABER data for 26-month QBO: (a) at year day 2003075 for March equinox, and (b) at year day 2002180 for June solstice. Bottom row for comparison between SABER and MLS results: (c) SABER results for 15 to $50 \mathrm{~km}$ and $32^{\circ} \mathrm{S}$ to $32^{\circ} \mathrm{N}$ from (a), and (d) for MLS results at year day 1993270 based on data between 1992 and 1994.

larger, and this is consistent with the larger eddy viscosity in that region.

The literature on observed temperatures for the QBO in the stratosphere is relatively limited, and we are not aware of published QBO temperature measurements in the mesosphere. For the middle and lower stratosphere, Dunkerton and Delisi (1985b) analyzed 20 years of radiosonde data, while Pawson and Fiorino (1998), and Huesmann et al. (2001) discuss temperature results from the National Centers for Environmental Prediction (NCEP) and the European Centre for Medium-Range Weather Forecasts Reanalysis (ERA). Randel et al. (1999) presented results from the United Kingdom Meteorological Office (UKMO) analysis. Remsberg et al. (2002) discuss the inter-annual tem- perature variations based on data from the Halogen Occultation Experiment (HALOE) on UARS over a period of 9.5 years (October 1991 through April, 2001). In the altitude range between about 35 and $50 \mathrm{~km}$, they detected variations with periods from 688 to 800 days (about 23 to 27 months). Their amplitudes are typically around $1.0^{\circ} \mathrm{K}$, compared with the present SABER values that are closer to $3^{\circ} \mathrm{K}$, but the results are only given at 2 and $3 \mathrm{hPa}$ (about 40 and $43 \mathrm{~km}$ ). As discussed below, our results for the semiannual component agrees much better with those of Remsberg et al. (2002). With lidar measurements at Mauna Loa, Hawaii $\left(19.5^{\circ} \mathrm{N}\right)$, Leblanc and McDermid (2001) have observed QBO signatures in the stratospheric temperatures with amplitudes approaching $5^{\circ} \mathrm{K}$, which are much larger than those 


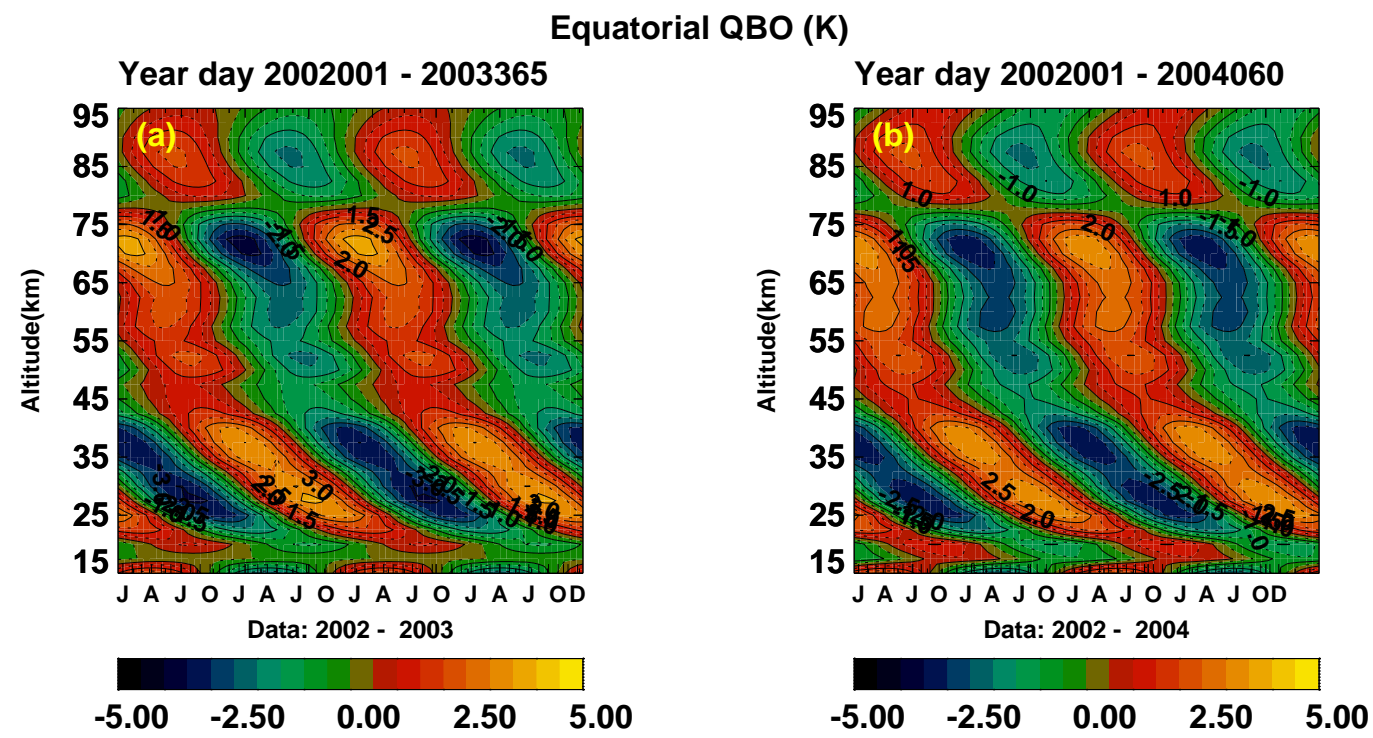

Fig. 5. Temperature variations at the Equator derived from SABER for QBO periods of 24 (a) and 26 (b) months, plotted versus altitude and month of year for two cycles. The results in (a) and (b) correspond to those presented in the top and bottom rows of Fig. 2 respectively.

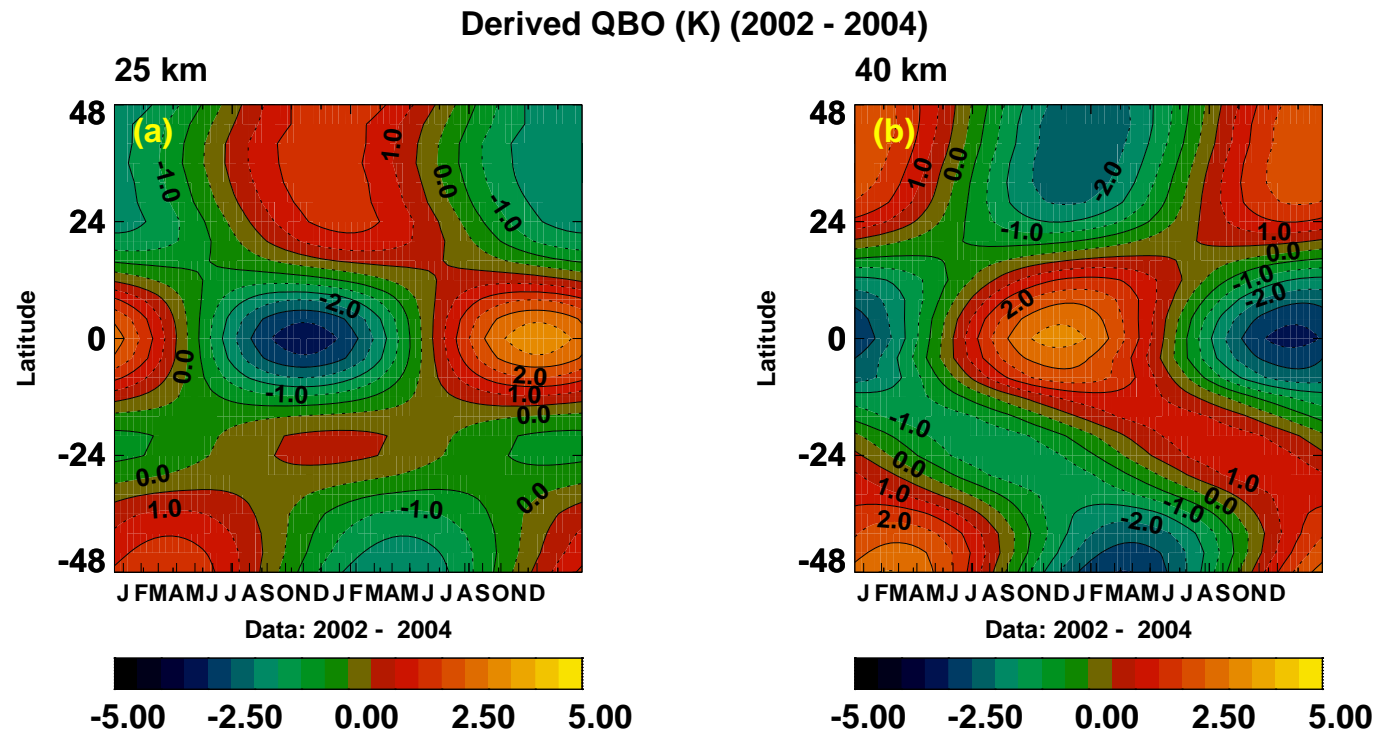

Fig. 6. For comparison with results from the United Kingdom Meteorological Office (UKMO) stratospheric assimilation (Randel et al., 1999), the QBO temperature variations based on SABER data at $25 \mathrm{~km}$ (a) and $40 \mathrm{~km}$ (b) are shown on latitude versus day coordinates.

inferred from SABER at this latitude. Contrary to our results for the mesosphere, Leblanc and McDermid (2001) also state that they have not detected any QBO temperature signatures from the lidar measurements above $60 \mathrm{~km}$.

It is well established that the zonal winds for the QBO are confined to low latitudes and peak near the Equator (Baldwin et al., 2001). Consistent with our SABER temperature results, a mesospheric QBO has been observed in the zonal winds with the HRDI instrument (Hays et al., 1993) on UARS (Burrage et al., 1996).

\section{Mid-latitude $Q B O$}

It can be seen from Fig. 2 that the QBO temperature amplitudes generally recover from a minimum between $15^{\circ}$ and $30^{\circ}$ to reach again larger values at mid latitudes that are comparable to those near the Equator. For solstice in Fig. 4b, the temperature variations poleward of $20^{\circ}$ latitude reveal evident asymmetries between the two hemispheres, which are not apparent in Fig. 4a for equinox. These asymmetries are apparent at least up to about $70 \mathrm{~km}$. Although not shown, 
the MLS results for solstice below about $50 \mathrm{~km}$ support the inferred asymmetry based on the SABER data. Since the global-scale meridional circulation is involved in generating the QBO temperature variations, and the meridional winds are directed across the equator from the summer to the winter hemisphere, it is reasonable to expect such asymmetries in the data. However, we have only two instances, and the observed asymmetries still could be coincidental.

Analogous to Fig. 5, we show with Fig. 6 the QBO temperature variations on latitude versus day of year coordinates based on 26-month SABER data at $25 \mathrm{~km}$ (a) and $40 \mathrm{~km}$ (b). As in the case for Fig. 4, the morphology is consistent with that from the UKMO stratospheric assimilation (Randel et al., 1999, Figs. 10, 11), where it is noted that the results at 25 and $40 \mathrm{~km}$ are mostly out of phase. The mid-latitude phase progression with altitude is markedly different from that at the Equator (Fig. 5), where the phase varies more gradually with altitude. For example, near 20, 50 and $75 \mathrm{~km}$ (not shown) the phases at $40^{\circ} \mathrm{S}$ to $48^{\circ} \mathrm{S}$ undergo abrupt changes.

We also have preliminary results (not shown) on temperature variations with longitude. Based on the SABER and MLS data, the results indicate that within about $20^{\circ}$ of the Equator, the QBO amplitudes vary little with longitude. At mid-latitudes, however, the apparent amplitude variations may approach 40 percent.

\subsubsection{Semiannual Oscillations (SAO)}

Analogous to Fig. 2, we present in Fig. 7 the amplitude (a) and phase (b) variations for the SAO temperatures obtained from the analysis of SABER data from years 2002, 2003, and 2004 merged together. The results are again shown on altitude ( 15 to $95 \mathrm{~km}$ ) versus latitude $\left(48^{\circ} \mathrm{S}\right.$ to $\left.48^{\circ} \mathrm{N}\right)$ coordinates. Corresponding results (not presented) based on data from individual years show that there are significant interannual variations in the amplitudes. As can be seen from Fig. 7, the temperature variations of the SAO are essentially symmetric with respect to the Equator. For the latitude range shown, the amplitudes tend to be largest close to the Equator, especially at altitudes below about $55 \mathrm{~km}$. Poleward of about $30^{\circ}$ latitude, the amplitudes tend to level off and then increase with latitude, especially above $55 \mathrm{~km}$.

\section{Equatorial SAO}

In the equatorial region (see Fig. 7, based on merged data from 2002, 2003, and 2004), our results for the stratospheric $\mathrm{SAO}$ (or SSAO) show an amplitude peak of about $5^{\circ} \mathrm{K}$ at $45 \mathrm{~km}$ altitude. At higher altitudes, it is evident from Fig. 7 that there are two separate amplitude peaks approaching $7^{\circ} \mathrm{K}$, one near $75 \mathrm{~km}$ and the second one near $90 \mathrm{~km}$. The inter-annual variations of the SAO, mentioned above, show that the inferred amplitudes are largest in 2002 compared to those of 2003 and 2004. An example is given in Fig. 8, in which the estimated semiannual temperatures are plotted at the Equator on altitude versus day of year coordinates. In the left panel (a), we show the analysis result for the combined 2002, 2003, and 2004 data, while the right plot (b) is based on data from 2002 only.

Remsberg et al. (2002) derived the amplitude and phase variations for the temperature of the SAO based on HALOE measurements on UARS, covering over 9.5 years (October, 1991 through April, 2001). The results are presented from 10 to $0.01 \mathrm{hPa}$ (about 32 to $80 \mathrm{~km}$ ) and from $40^{\circ} \mathrm{S}$ to $40^{\circ} \mathrm{N}$. The contour plots (from Fig. 4 of their paper, not shown) can be compared directly with our Fig. 7, and show that the SAO amplitude and phase variations for the measured temperatures on UARS (HALOE) and TIMED (SABER) are in qualitative agreement. At the Equator, both data sets produce peak amplitudes of about $6^{\circ} \mathrm{K}$ centered between 70 and $75 \mathrm{~km}$, but the apparent peak of about $2^{\circ} \mathrm{K}$ in the amplitudes based on HALOE data near $40 \mathrm{~km}$ is only about half as large as the one inferred from SABER. Remsberg et al. (2002) do not provide results above $80 \mathrm{~km}$, and therefore cannot verify the amplitude peak we find near $90 \mathrm{~km}$.

For our SAO results near $90 \mathrm{~km}$ however, we believe that the analysis by Garcia et al. (1997) does provide some confirmation. They analyzed the temperature data from the Solar Mesosphere Explorer (SME) satellite (measured by the ultraviolet spectrometer (UVS) from 40 to $92 \mathrm{~km}$, years 1983 to 1986) and from rocketsondes at Kwajalein $\left(8.7^{\circ} \mathrm{N}, 167.7^{\circ} \mathrm{W}\right)$ and Ascension $\left(7.6^{\circ} \mathrm{S}, 14.4^{\circ} \mathrm{W}\right)$ islands. The rocketsonde measurements covered altitudes from the ground to $63 \mathrm{~km}$, years 1969 to 1987 . The results by Garcia et al. (not shown here) were presented for the combined annual, semiannual, and ternary harmonics, and they were plotted on altitude versus latitude coordinates. For comparison, we present with Fig. 9 the corresponding results based on SABER data at the Equator, which also contain the combined annual, semiannual and ternary components. The left panel (a) is based on data from year 2002 and the right plot (b) is based on data from year 2003 to show inter-annual variations.

In Fig. 9, the altitudes from about 15 to $60 \mathrm{~km}$ cover the range for the temperature observations by Garcia et al. (1997) at Kwajalein and Ascension islands. Our SABER results agree morphologically with those published by Garcia et al. But their temperature variations are smaller than ours, with lows and highs being generally between -2 and $4^{\circ} \mathrm{K}$, respectively. As they point out, the sounding rocket data were averaged into months and otherwise smoothed to study the seasonal cycles. Moreover, the rocketsonde data were taken primarily during the early afternoon hours, so that they were biased by thermal tides. Both the rocketsonde and our results show that the annual cycle starts to dominate near the tropopause, although the transition from the semi-annual cycle occurs in the SABER data at altitudes 2 or $3 \mathrm{~km}$ higher. For the Garcia et al. results based on SME data at the Equator, the inferred SAO temperature variations cover the altitude range from 40 to $92 \mathrm{~km}$. Our derived SAO temperatures 

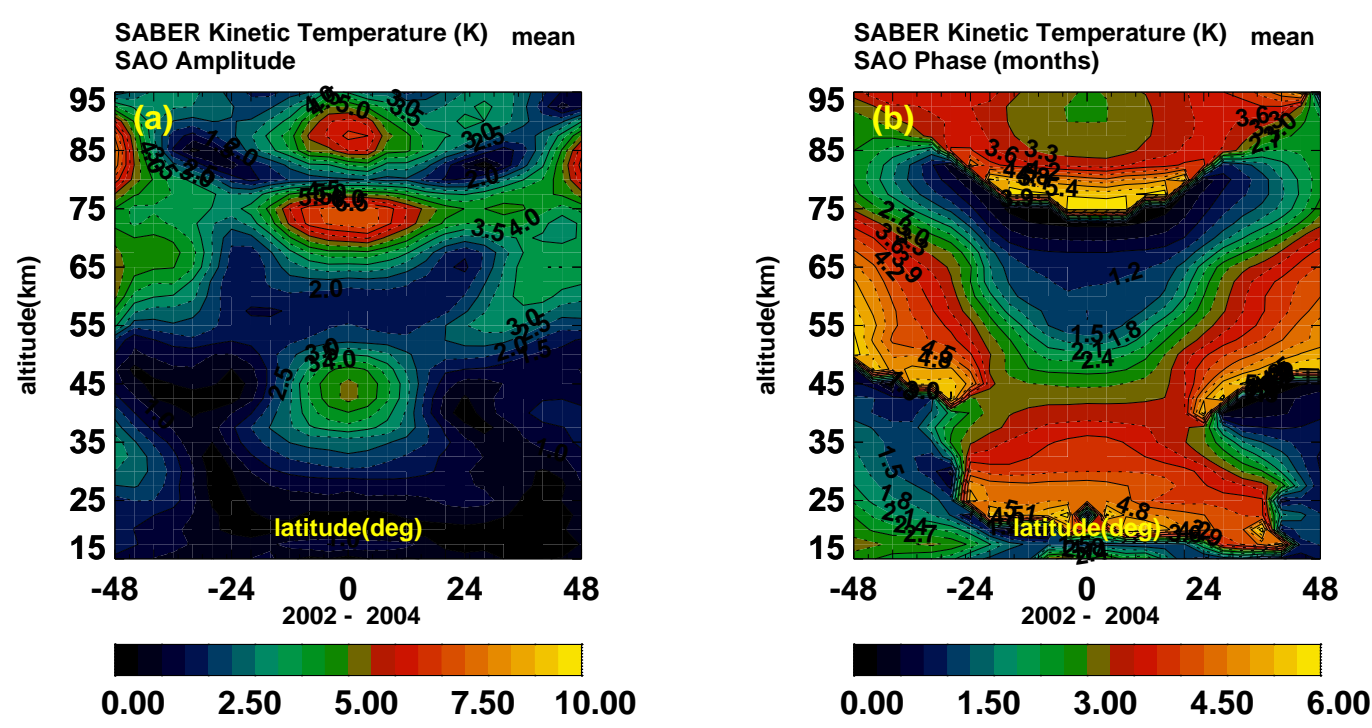

Fig. 7. Amplitudes (left) and phases (right) for derived SAO temperature variations based on SABER data, plotted versus altitude (15 to $95 \mathrm{~km}$ ) and latitude $\left(48^{\circ} \mathrm{S}\right.$ to $\left.48^{\circ} \mathrm{N}\right)$. The data from years 2002, 2003, and 2004 were merged together to derive the SAO.

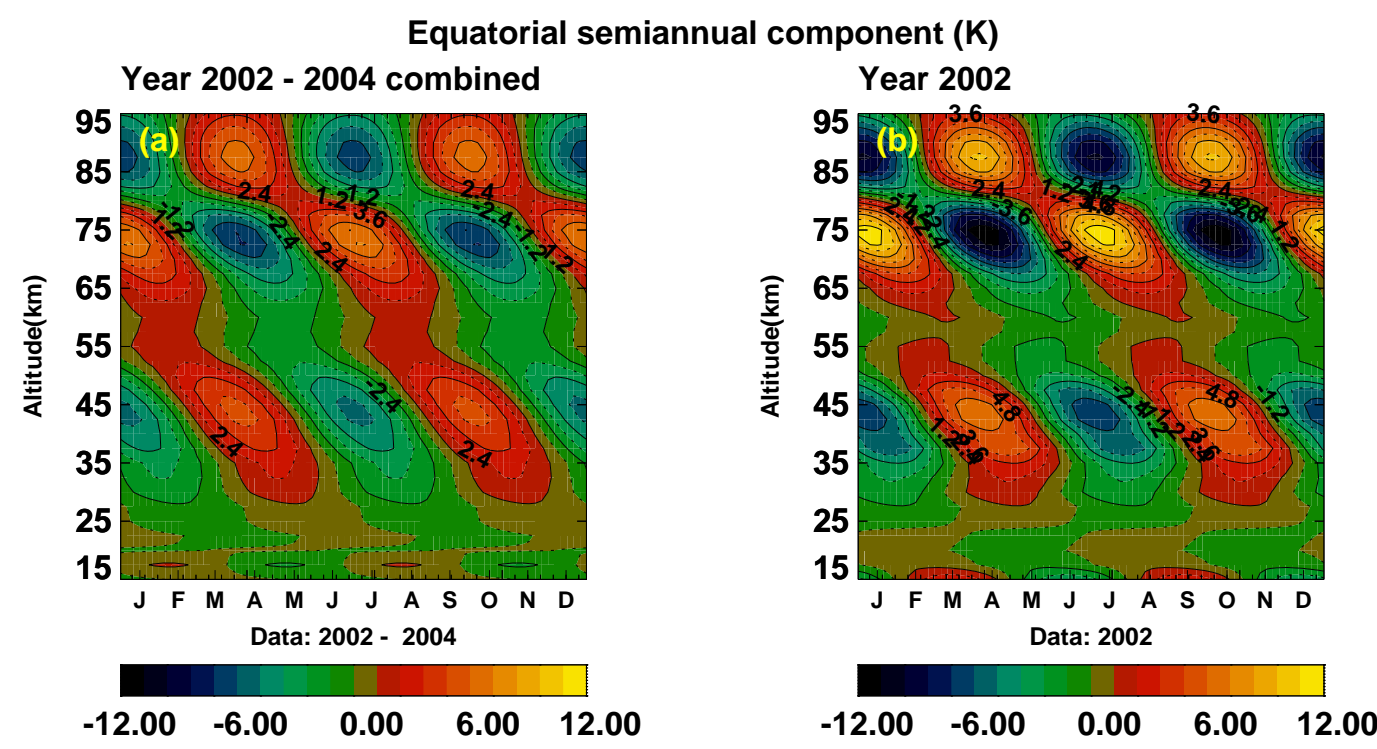

Fig. 8. SABER derived temperature variations for the SAO are shown at the Equator plotted on altitude versus day coordinates. (a) Corresponds to Fig. 7 for years 2002 to 2004 merged together, and (b) for comparison from year 2002 to illustrate the inter-annual variability of the SAO.

are more consistent with the rocketsonde results than with the SME data, although there is general agreement that the semiannual component tends to dominate. Between 60 and $80 \mathrm{~km}$, the SME values are generally between $-4^{\circ} \mathrm{K}$ and $4^{\circ} \mathrm{K}$, and are smaller than our highs and lows, as can be seen from Fig. 9a. From our figure, it can also be seen that relatively rapid phase changes with altitude occur near $80 \mathrm{~km}$, and this feature is also evident in the SME results. Unlike the situation at lower altitudes, the SME temperature amplitudes above $85 \mathrm{~km}$ can approach $16^{\circ} \mathrm{K}$ and are significantly larger than our highs and lows of about $\pm 8^{\circ} \mathrm{K}$. Otherwise, the amplitudes aside, our results track the SME data very closely in time. Garcia et al. (1997) question the accuracy of the large SAO values and the morphology based on SME data. They note that above $85 \mathrm{~km}$, the SME results are not consistent with (a) the corresponding vertical shears of the zonal winds from the High Resolution Doppler Imager (HRDI) on the Upper Atmosphere Research Satellite (UARS) satellite, 


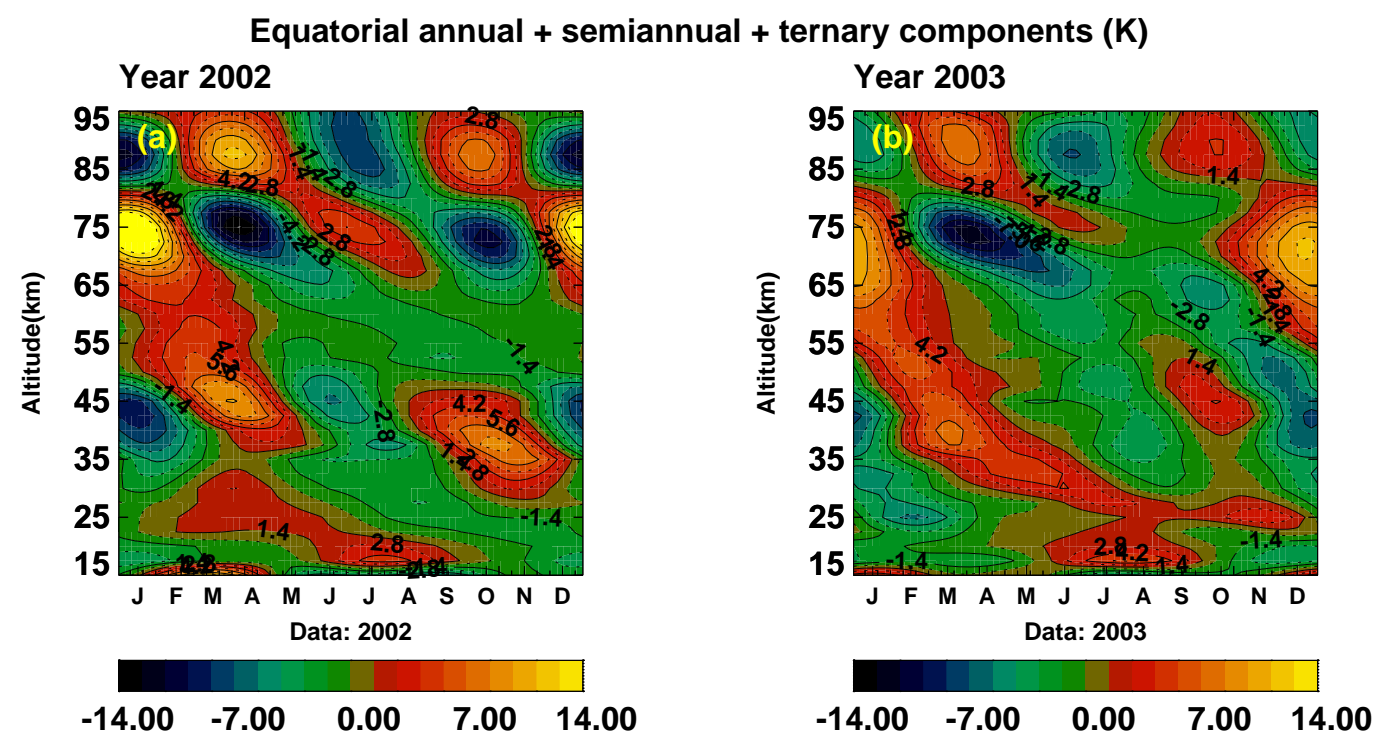

Fig. 9. Similar to Fig. 8 but showing the derived combined annual, semiannual, and ternary components at the Equator based on SABER measurements. (a) Based on data from year 2002; (b) for year 2003 to illustrate inter-annual variability.

(b) with the results from sounding rockets at Ascension and Kwajalein Islands, and (c) with the MF radar measurements at Christmas Island $\left(2^{\circ} \mathrm{N}, 157^{\circ} \mathrm{W}\right)$. They also noted that the diurnal tides in the SME data were not accounted for, and the zonal averages could be biased because the longitude coverage was not uniform. Notwithstanding these difficulties, the two peaks in the SAO temperature amplitude derived from the SABER measurements in the mesosphere are qualitatively consistent with the results from SME near $90 \mathrm{~km}$. In contrast to SME, the TIMED mission samples all local times, and the algorithm we use effectively removes the tidal component from the SABER data. As shown in the next section, the amplitudes for the diurnal tide can approach $20^{\circ} \mathrm{K}$.

Fleming et al. (1990, COSPAR International Reference Atmosphere) report peak amplitudes of about $4^{\circ} \mathrm{K}$ for the inferred SAO temperatures near $40 \mathrm{~km}$ and $80 \mathrm{~km}$, which is comparable to ours and larger than that of Remsberg et al. (2002) in the stratosphere, but is smaller than ours and that of Remsberg et al. in the mesosphere. They do not show an amplitude peak near $90 \mathrm{~km}$, as we do. The phase variations are similar to ours, with some differences in details. The SAO temperature amplitudes derived by Shepherd et al. (2004) from measurements by the Wind Imaging Interferometer (WINDII) on UARS at $75 \mathrm{~km}$ agree to about 10 to 15 percent, while the phases generally differ by less than one month.

In addition to the effects from tidal variations and other problems mentioned earlier, there are other possible reasons for the differences between our results and those of others. The data with which we compare often cover a longer time span, and our zonal means are not averaged in time such as in monthly bins. In addition, other results generally use one set of amplitudes and phases to represent the entire multi-year data sets.

For the zonal winds of the SAO at the Equator, peak amplitudes have been reported in the stratosphere near $45 \mathrm{~km}$ and in the mesosphere near $80 \mathrm{~km}$ (Hirota, 1978; Balwin et al., 2001).

\section{Mid-latitude SAO}

From Fig. 7 it is apparent that the derived SAO temperature amplitudes, between $48^{\circ} \mathrm{S}$ and $48^{\circ} \mathrm{N}$, tend to peak at the Equator. Above about $55 \mathrm{~km}$, however, the amplitudes increase again pole-ward of about $30^{\circ}$ latitude. At $48^{\circ}$ in both hemispheres, the amplitudes reach several ${ }^{\circ} \mathrm{K}$ near 35 , 60 , and $80 \mathrm{~km}$, and one might expect that they would continue to increase further at higher latitudes. Analogous to Fig. 8, we show in Fig. 10 the estimated semiannual temperature amplitudes $\left({ }^{\circ} \mathrm{K}\right)$ on altitude versus day coordinates at $44^{\circ} \mathrm{S}$ (a) and $44^{\circ} \mathrm{N}$ (b), based on data from years 2002-2004 merged into one 365-day period. The existence of substantial temperature amplitudes at mid-latitudes is qualitatively consistent with results based on lidar measurements (Leblanc et al., 1998), from stations at $44^{\circ} \mathrm{N}$ in France (Observatoire de Haute Province (OHP) and Centre d'Essais des Landes (CEL)) and at $40.6^{\circ}$ (Colorado State University (CSU)). The results of Remsberg et al. (2002) do not extend past $40^{\circ}$, but they indicate also that the amplitudes recover at mid-latitudes though with smaller magnitudes than those reported here. 


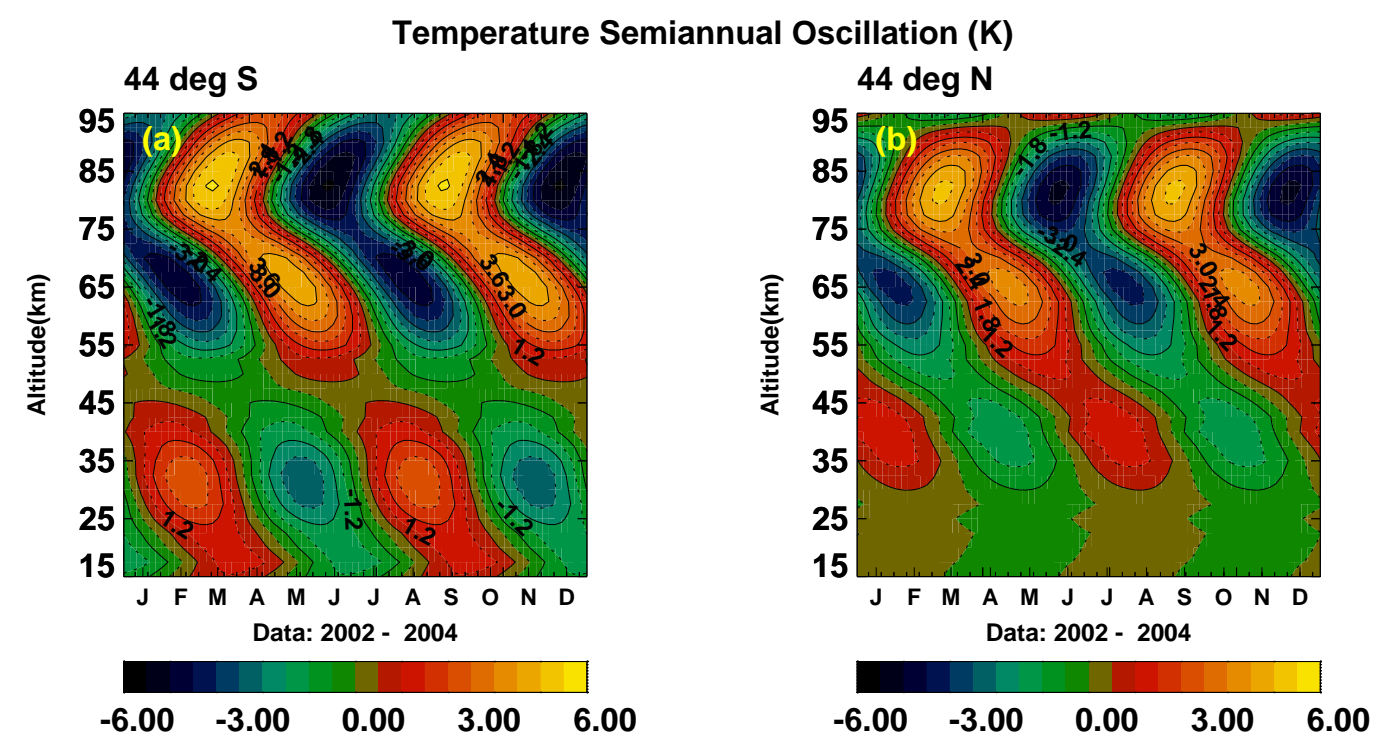

Fig. 10. Analogous to Fig. 8 but showing the derived temperature variations for the SAO at $44^{\circ} \mathrm{S}$ (a) and $44^{\circ} \mathrm{N}$ (b) based on SABER data from years 2002 to 2004 merged together.

\subsection{Diurnal tides}

We recall that in their discussion of the SAO, Garcia et al. (1997) emphasized that the sun-synchronous SME and the rocketsonde measurements did not provide information on the diurnal variations, and they questioned therefore the accuracy of their results. As mentioned above, over a period of 60 (SABER) and 36 (MLS) days, the data are sampled over the range of local times, and our algorithm accounts for the variations of the tides. Although the focus of this paper is not on thermal tides, for completeness we present some of the results that bear on their inter-annual variations.

In Fig. 11, we present the derived amplitudes for the diurnal migrating tide based on SABER temperatures at $75 \mathrm{~km}$. The panels (a), (b), (c) show the results for the years 2002, 2003, 2004, respectively, plotted on latitude versus day of year coordinates, and the lower right panel (d) shows the diurnal migrating tide amplitudes for year day 2002080 on altitude-latitude coordinates. Corresponding to Fig. 11, the tidal results for $95 \mathrm{~km}$ are shown in Fig. 12. The lower right panel (d) of Fig. 12 shows the temperature migrating tide diurnal amplitudes for year 2002 at the Equator on altitude versus day of year coordinates. In panels (d) of Figs. 11 and 12 , near the maximum values, we have allowed the colors to saturate so that the colors near minimum values can be discerned more easily. Characteristic for the propagating diurnal tide, the temperature amplitude peaks at the equator and near equinox. In the context of the present paper, the tide also varies significantly from year to year, presumably under the influence of the QBO. Such inter-annual variations of the diurnal tide have also been reported by Burrage et al. (1996) based on wind measurements with the HRDI instrument on UARS (Hays et al., 1993).

\section{Numerical Spectral Model (NSM) results}

For comparison with the above observations, we present here the numerical results from a study with the Numerical Spectral Model (NSM) in which the inter-annual variations of the diurnal tide were generated by the wave-driven Quasibiennial Oscillation (Mayr and Mengel, 2005, referred to as MM). No attempt was made in this model run to tune the NSM to reproduce the measurements. The model comparison is of interest since it documents where we presently stand with the NSM and thereby illustrates some of our difficulties in simulating the observed equatorial oscillations (i.e., QBO and $\mathrm{SAO}$ ).

In the following, we briefly describe the NSM and the specific model run in MM from which the numerical results are taken. We then present the computed zonal mean temperature variations that characterize the QBO and SAO. For the diurnal tide, we refer to the inter-annual variations of the temperature amplitude that are shown in Fig. 2e of MM.

The MM version of the NSM is integrated from the Earth's surface into the lower thermosphere and is driven for the zonal mean $(\mathrm{m}=0)$ by ultraviolet radiation in the mesosphere, and in the stratosphere the heating is taken from Strobel (1978), and by extreme ultraviolet radiation absorbed in the thermosphere. For $\mathrm{m}=0$, tropospheric heating is applied to reproduce qualitatively the observed zonal jets near the tropopause and the accompanying latitudinal temperature variations. The migrating tides are driven by the excitation sources in the troposphere and stratosphere (Forbes and Garret, 1978), and non-linear interactions between migrating tides and planetary waves generate the non-migrating tides. Since the model does not have topography, the planetary waves are generated solely by instabilities. The radiative 

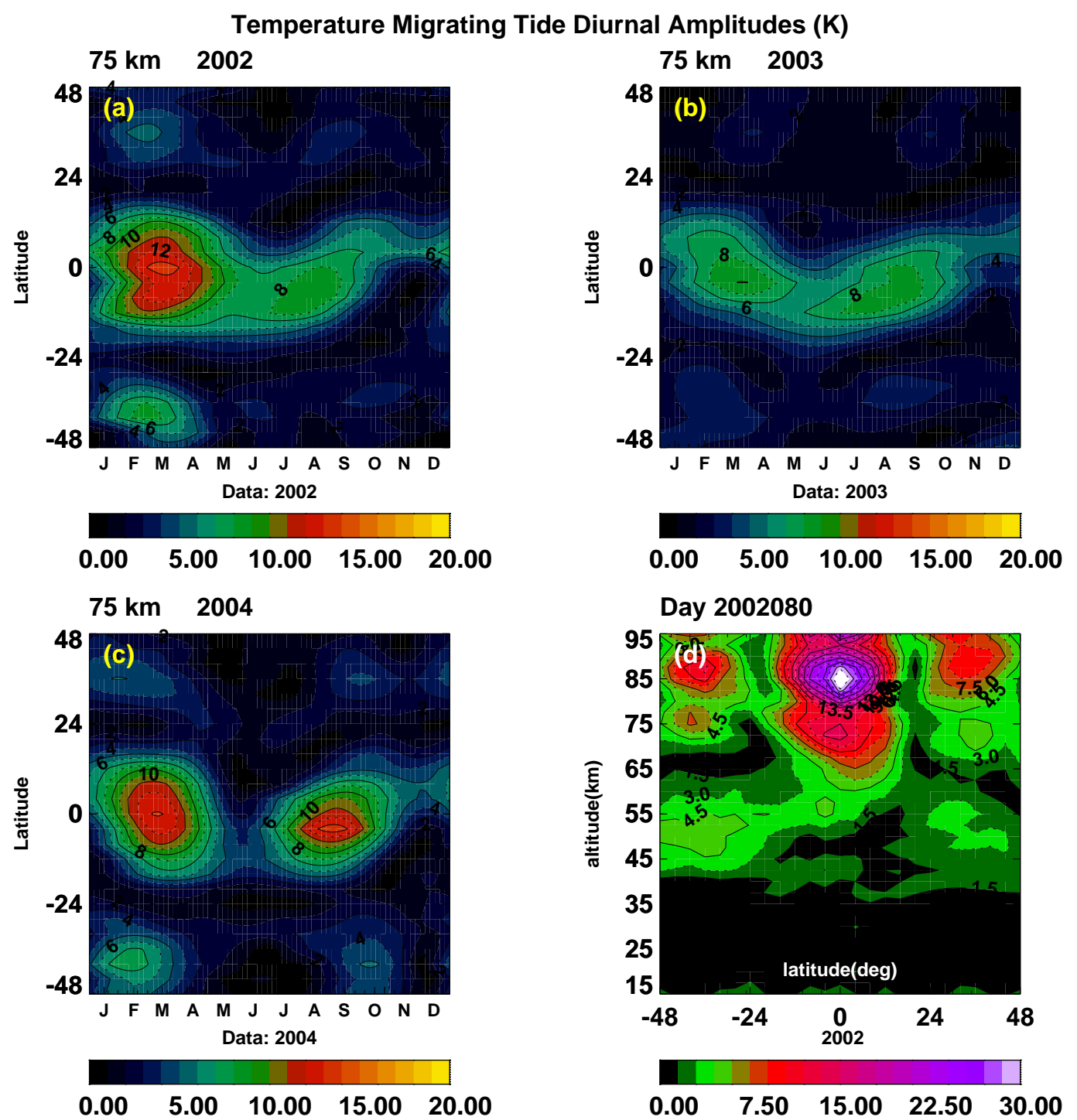

Fig. 11. For the migrating diurnal tide, the temperature amplitudes are presented at $75 \mathrm{~km}$, which are derived from the SABER data jointly with the earlier discussed zonal-mean components. Plotted versus latitude ( $48^{\circ} \mathrm{S}$ to $48^{\circ} \mathrm{N}$ ) and month of year for 2002 (a), 2003 (b), and 2004 (c) to illustrate the inter-annual variability of the tide. Lower right (d): Diurnal tidal amplitudes for day 2002080 on altitude versus day coordinates.

loss is described in terms of Newtonian cooling adopted from Zhu (1989), which is modified to keep the radiative relaxation rate constant below $20 \mathrm{~km}$.

An integral part of the NSM is that it incorporates the Doppler Spread Parameterization (DSP) for small-scale gravity waves (GWs) developed by Hines (1997a, b). The DSP deals with a spectrum of waves that interact with each other to produce Doppler spreading, which affects the GW interactions with the flow. To account for the enhanced wave activity in the tropics due to convection, the GW source in MM is assumed to peak at the equator - and this contributes to generate the stronger QBO zonal wind amplitudes in the stratosphere that are fairly realistic in this model run. Since there is very little observational guidance, the GW parameters were chosen simply from the middle of the range recommended for the DSP. The non-linear DSP is implemented with Newtonian iteration, and convergence is enforced by adjusting the time integration step that is typically $5 \mathrm{~min}$. With the upper boundary at about $130 \mathrm{~km}$, an integration step of about $0.5 \mathrm{~km}$ is chosen to resolve the GW interactions with the flow, but the NSM is truncated at the zonal and meridional wave-numbers $m=4$ and $n=12$, respectively.

\subsection{QBO model}

The QBO generated by the NSM in MM has a period that varies between about 22 and 30 months, which qualitatively 


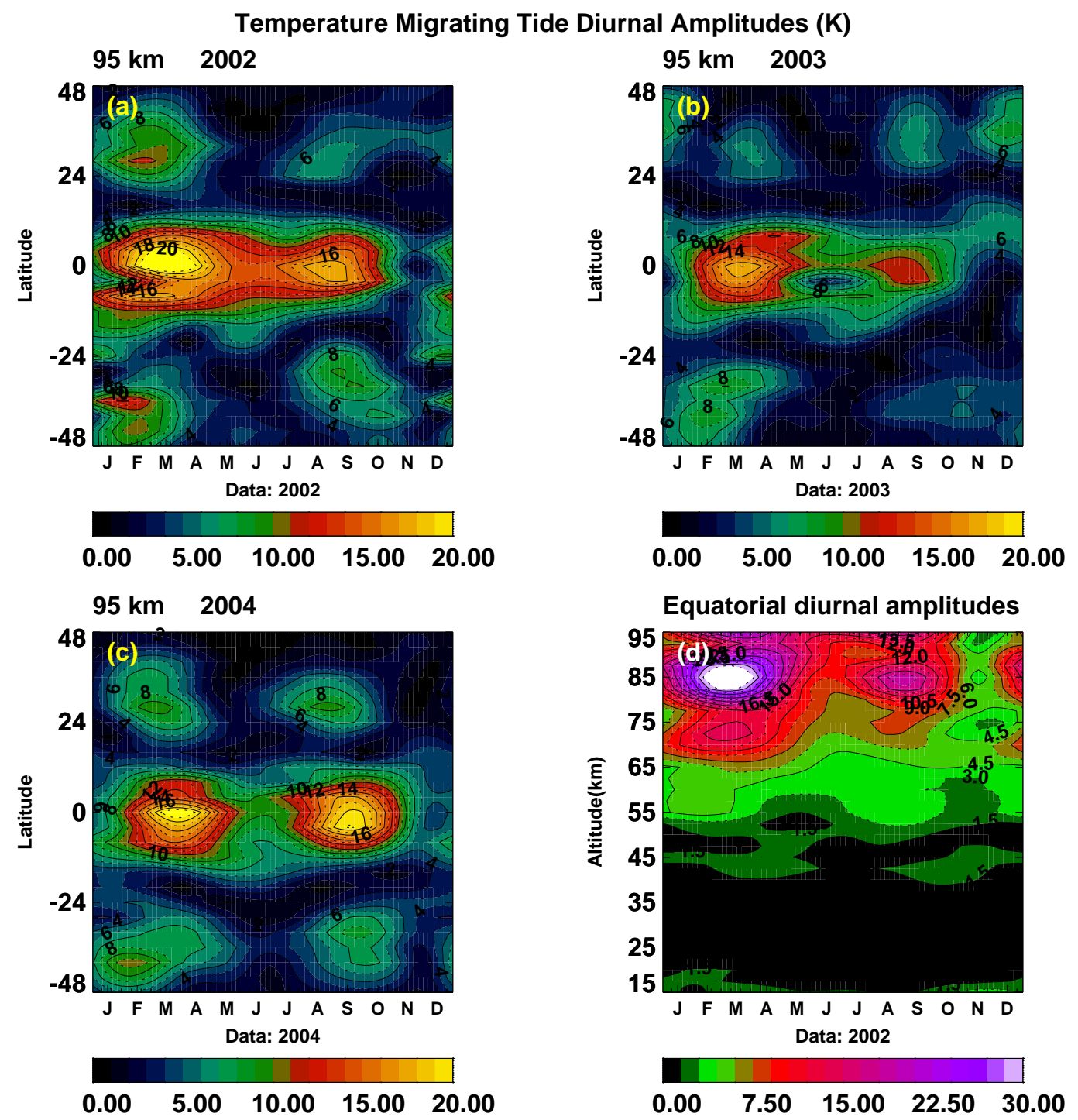

Fig. 12. Upper row and lower left (a), (b), (c): Similar to Figu. 11 but for derived year-to-year variations of the migrating diurnal tide at $95 \mathrm{~km}$, for years 2002, 2003, 2004. Lower right (d): Migrating diurnal tidal amplitudes for 2002 at the Equator on altitude versus day coordinates.

mimics the variability that is observed. To get modeled QBO results that are fairly stable for at least 2 cycles, we chose the time segment after year 17 where the period is close to 24 months. For that period, we present in Fig. 13 the amplitude and phase variations of the computed QBO temperatures. This shows that the temperature amplitudes in the stratosphere below $60 \mathrm{~km}$ approach values close to $2^{\circ} \mathrm{K}$, which are smaller than those observed (exceeding $3^{\circ} \mathrm{K}$ ) below $40 \mathrm{~km}$ (see Fig. 2). In qualitative agreement with the SABER measurements, the model generates a mesospheric temperature QBO above $60 \mathrm{~km}$, but the amplitude there is only $1^{\circ} \mathrm{K}$ compared to the measured values of about $3^{\circ} \mathrm{K}$. In contrast to the modeled zonal winds, the temperature variations of the $\mathrm{QBO}$ are not confined to the equatorial region. This is in qualitative agreement with the measurements, including the phase reversals at latitudes away from the equator. Hemispherical asymmetries also appear in both the model results and the observations. However, the temperature amplitudes outside the equatorial region tend to occur at lower latitudes in the model results.

For comparison with the observed QBO temperature variations at the Equator (see Fig. 5), we present in Fig. 14 the corresponding model results for $4^{\circ}$ latitude (Gaussian point). This shows the downward phase progression that characterizes the QBO zonal winds at the Equator. In qualitative agreement with the observations, the downward phase velocity increases from the stratosphere into the mesosphere. However, that phase speed increases roughly from about 1.3 to $3 \mathrm{~km} / \mathrm{month}$ in the observations and from about 1 to $1.8 \mathrm{~km} /$ month in the model results. 


\subsection{SAO model}

Analogous to Fig. 13, we present in Fig. 15 the computed SAO temperature variations obtained from the same time segment in the model run from which the QBO results are taken from. From the model years 18 to 20, the 6-month oscillation is derived by taking the 4th harmonic. Near the Equator at $45 \mathrm{~km}$ in the stratosphere, the computed amplitude of about $3.5 \mathrm{~K}$ agrees with the values that are observed (see Fig. 7). At this altitude, the phase from the model is in agreement with that observed. In qualitative agreement with the SABER measurements, amplitude maxima are also generated in the mesosphere at 75 and near $90 \mathrm{~km}$ altitudes. However, the modeled peak amplitude at $75 \mathrm{~km}$ is only $3.5 \mathrm{~K}$ compared to the observed value that is closer to $5 \mathrm{~K}$. In agreement with the measurements, the model SAO temperature amplitudes peak near the Equator and increase again towards mid latitudes. As seen also in the QBO model results, the SAO temperature amplitudes away from the Equator peak at lower latitudes than those observed.

With Fig. 16 we show the computed SAO temperature variations near the Equator. In agreement with the measurements (Fig. 8), the temperature maxima at $45 \mathrm{~km}$ occur near equinox. The observed downward phase progression is also reproduced by the model. However, the observed phase speed of about $8 \mathrm{~km} / \mathrm{month}$ is about twice as large as that produced in the model. As a result, the computed temperature variations in the upper mesosphere are out of phase when compared with the observations.

\section{Discussion and summary}

Based on satellite measurements from the SABER (TIMED) and MLS (UARS) instruments, we derive the zonal-mean temperature variations for the QBO and SAO in the stratosphere and mesosphere. The SABER results cover the altitude range from 15 to $95 \mathrm{~km}$, and complementary results were derived from MLS data from a decade earlier from about 16 to $48 \mathrm{~km}$. The results are presented for latitudes from $48^{\circ} \mathrm{S}$ to $48^{\circ} \mathrm{N}$, and we compare them with corresponding results published in the literature. New results are obtained for the QBO, especially in the upper stratosphere and mesosphere, and at mid-latitudes where there has been a dearth of observations. Much of the SAO results are also new, either because measurements were not available before, or were limited to some extent. Since the diurnal tides are an integral part of the data, we present some results to describe their inter-annual variations that may be tied to the QBO.

\subsection{QBO observations}

Based on the SABER data, we have estimated the QBO temperature variations by assuming periods from 24 to 29 months. We have found that, irrespective of the assumed
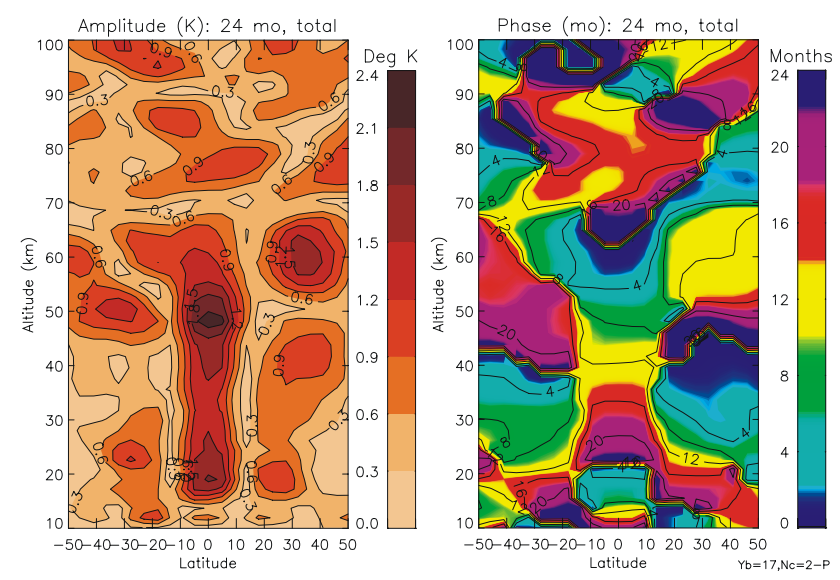

Fig. 13. Computed amplitude and phase for a period of 24 months taken from the NSM run in Mayr and Mengel (2005, referred to as $\mathrm{MM})$. The time segment analyzed covers two cycles for the period from model years 18 to 22 when the QBO is relatively stable.

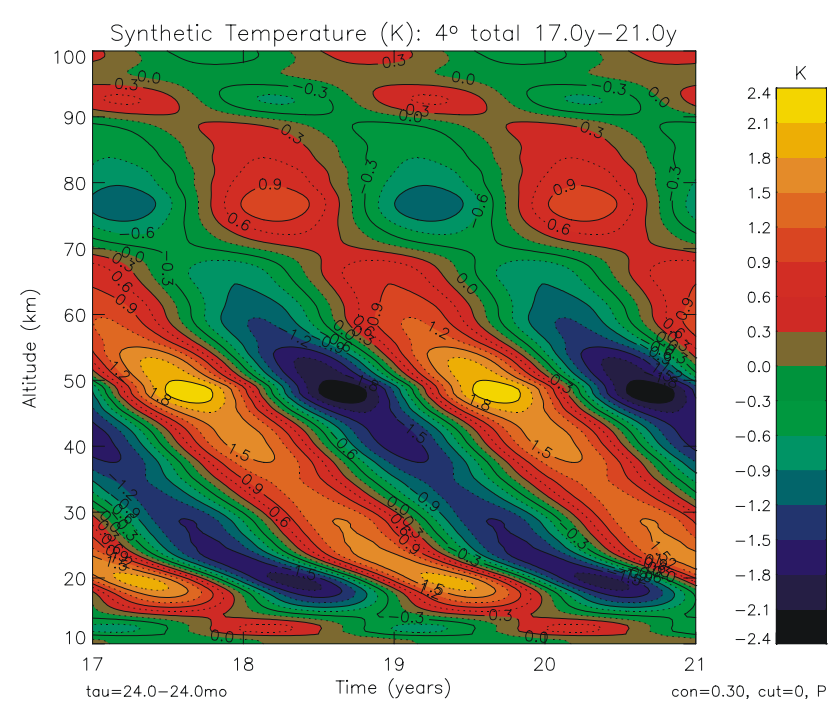

Fig. 14. Temperature variations near the Equator for the 24-month QBO computed in the model.

QBO period, the salient features of the inferred oscillations are qualitatively similar.

At Equatorial latitudes, the QBO reveals local peaks, albeit small, at different altitudes. Within about $15^{\circ}$ of the Equator and from about 20 to $40 \mathrm{~km}$ altitude, the amplitudes can approach $3.5^{\circ} \mathrm{K}$ in the stratospheric QBO. In the mesospheric QBO, we find separate peaks near $70 \mathrm{~km}$, with the temperature amplitudes reaching about $3.5^{\circ} \mathrm{K}$; and near $85 \mathrm{~km}$, the amplitudes approach $2.5^{\circ} \mathrm{K}$. However, the QBO peak near $70 \mathrm{~km}$ is more sensitive to the assumed period, being larger for the 24- and 26-month oscillations.

The morphology of the QBO temperatures based on MLS measurements, taken about ten years earlier than those from 

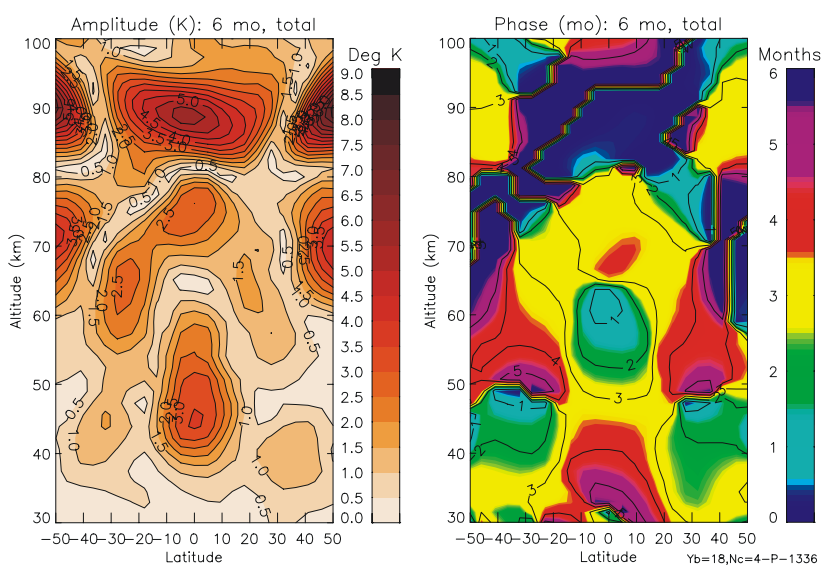

Fig. 15. Analogous to Fig. 13 but for the amplitude and phase variations of the SAO generated in the NSM.

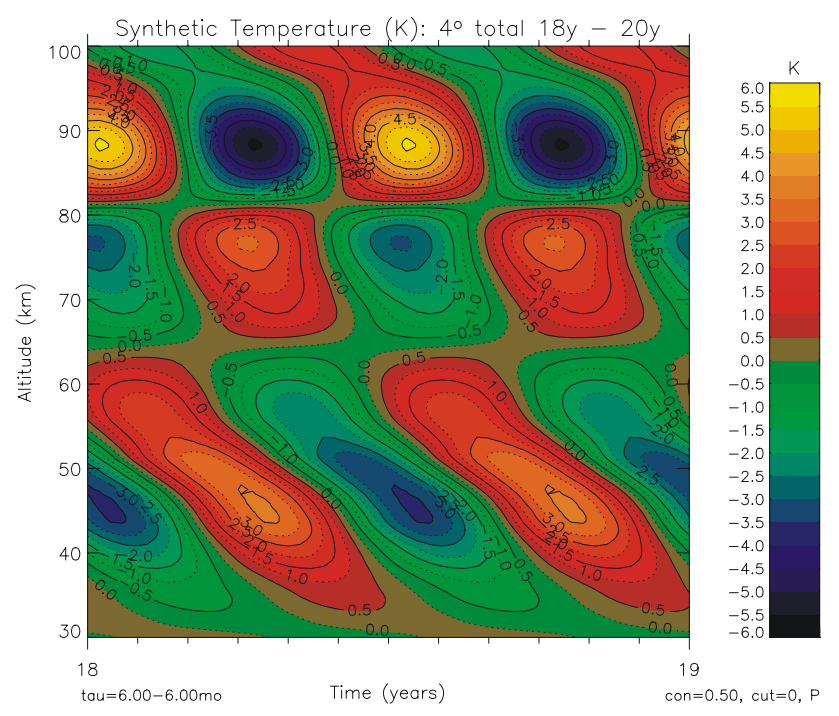

Fig. 16. Analogous to Fig. 14 but for the SAO temperature variations near the Equator that are generated in the NSM.

SABER, are qualitatively consistent with the SABER data. Between 20 and $45 \mathrm{~km}$ altitude, our SABER and MLS results are both also qualitatively consistent with the UKMO model assimilation (Randel et al., 1999), including the phase reversals with latitude and altitude. Our results show that the phase reversals extend to higher altitudes, but in the mesosphere there are no UKMO or MLS data with which to compare. The amplitudes generally decrease away from the Equator but then recover to reach again substantial magnitudes at mid latitudes. At mid-latitudes, the phase progression with altitude is markedly different from that at the Equator, where the changes occur more gradually.

Preliminary results for the longitude dependence of the QBO, based on SABER and MLS data, indicate that the amplitudes vary little within about $20^{\circ}$ of the Equator. At mid- latitudes, however, the apparent variations with longitude can approach 40 percent.

\subsection{SAO observations}

At altitudes between 40 and $45 \mathrm{~km}$, within about $15^{\circ}$ of the Equator, the semiannual amplitudes from SABER reach a local maximum of about $5^{\circ} \mathrm{K}$ for the stratospheric SAO. At higher altitudes, also within about $15^{\circ}$ of the Equator, the derived amplitudes show separate peaks of about $7^{\circ} \mathrm{K}$ near $75 \mathrm{~km}$ and $90 \mathrm{~km}$ for the mesospheric SAO. The inferred SAO varies from year to year, with the amplitudes being largest in 2002 compared to 2003 and 2004. Our SAO results for amplitude and phase are in qualitative agreement with those obtained by Remsberg et al. (2002), which are based on HALOE measurements at altitudes from 32 to $80 \mathrm{~km}$. (The match is much better than that for the QBO.) At the Equator, their amplitudes show a local maximum of about $6^{\circ} \mathrm{K}$ near $70 \mathrm{~km}$, which is in substantial agreement with our results; but near $40 \mathrm{~km}$, the local maximum they derive is about $2^{\circ} \mathrm{K}$, about half of our value. Remsberg et al. (2002) do not present results above $80 \mathrm{~km}$ and therefore cannot confirm the separate SAO peak we find near $90 \mathrm{~km}$. We believe that some supporting evidence for this second peak is provided by Garcia et al. (1997), who analyzed the temperature data from the SME satellite and from the rocketsondes at Kwajalein and Ascension islands. The morphology of the rocketsonde results at the Equator agrees well with our results, although the amplitudes are smaller than ours. In general, our results are in better agreement with the data from rocketsondes than those from SME. At $90 \mathrm{~km}$, however, the SAO temperatures inferred from SME are consistent with the peak we get at that altitude, although Garcia et al. (1997) question the accuracy of the large values they derived.

Our SAO amplitudes generally decrease away from the Equator but then recover again to reach substantial magnitudes at mid latitudes, especially at altitudes above $55 \mathrm{~km}$.

Clearly, much more analysis is required to describe in greater details the phenomena discussed here. As more data become available over longer time spans, the SABER measurements, for example, will provide valuable additional information on the seasonal, inter-annual and longer-term variations that characterize the climatology of the stratosphere and mesosphere.

\subsection{Model comparison}

The comparison between the observations and the model results is teaching us valuable lessons. For the lower stratosphere we learn that the model QBO temperature amplitudes are weaker than those observed. This is not surprising considering that the modeled zonal winds are also somewhat anemic. In the model discussed here, the QBO and SAO are generated primarily with GWs, and it is likely that the addition of planetary waves will alleviate this problem. 
In contrast to GWs, which tend to propagate isotropically, different kinds of planetary waves (i.e., Kelvin waves and Rossby gravity waves) are involved in providing the eastward and westward accelerations. The addition of planetary waves thus requires that their individual contributions to the momentum source be carefully balanced. It was shown in Mayr et al. (1999) that QBO-like zonal wind oscillations can be generated by the NSM, but the eastward propagating Kelvin waves and westward propagating Rossby gravity waves had to be carefully tuned for this purpose.

While the model generates QBO and SAO temperature variations in the mesosphere, the resulting amplitudes tend to be significantly weaker than those observed. A more serious problem is that the phase for the SAO generated in the model is opposite that observed. It is not clear where the solution might be found for the difficulties the NSM encounters in simulating the mesospheric equatorial oscillations. But the latitude dependence of the extra tropical temperature maxima, which occur in the model closer to the Equator than that observed, may provide a clue. The temperature observations suggest that the equatorial maximum for the $\mathrm{GW}$ source in the model may have been too narrow. With a wider wave source, the meridional circulation would redistribute the energy to higher latitudes and thus push the resulting extra-tropical temperature peaks away from the Equator. A wider wave source would also make the meridional circulation more effective in general, and this would increase the dissipation rate for the wave-driven equatorial oscillations. Such an increase would increase the modeled phase velocities of the QBO and SAO to bring them closer to the values that are observed. The increased dissipation rate could be compensated by increasing the GW source and stay within acceptable limits.

There are still other avenues to improve the performance of the NSM. One in particular involves the GW source spectrum in the troposphere, which is not well known. In the MM version of the NSM, a lower cut-off was applied to the vertical wave numbers of the spectrum in order to cause the eddy viscosity to level off at altitudes above $80 \mathrm{~km}$. While this is a desirable property, it also has the effect of cutting off the GWs that reach the upper mesosphere. Numerical studies will be required to determine how the various GW parameters, within acceptable limits, affect the solution and whether there is a solution that can match the observations. The observations presented here thus provide valuable information, though circumstantial, bearing on the wave forcing of the middle atmosphere that has received increased attention during the last decade.

\section{Appendix A}

\section{Algorithm}

With independent variables being local solar time and day of year, the data are described analytically in the form of a two dimensional Fourier series

$\Psi\left(t_{l}, d, z, \theta\right)=\sum_{n} \sum_{m} b_{n m}(z, \theta) e^{i 2 \pi n t_{l}} e^{i 2 \pi m d / 365}(\mathrm{~A} 1)$

where $\Psi\left(t_{l}, d, z, \theta\right)$ are the zonal means of the data; $z$ is altitude; $d$ day of year; $\theta$ colatitude, $t$ time (fraction of a day); $t_{l}$ local solar time (fraction of a day); $t_{l}=t+\lambda /(2 \pi)$, $\lambda=$ longitude.

The algorithm minimizes the sum of the squares of the differences between the Fourier series (Eq. A1) and the data over the fundamental period. Once the coefficients $\left\{b_{n m}(z, \theta)\right\}$ are estimated, both the zonal-mean winds and the tidal variations with local time can be calculated directly from Eq. (1) for a given day of year. More details concerning the algorithm and applications to UARS data are given in Huang et al. (1997) and Huang and Reber (2001, 2003).

Acknowledgements. We thank two anonymous reviewers for their insightful and helpful comments.

Topical Editor U.-P. Hoppe thanks M. H. Hirchman and another referee for their help in evaluating this paper.

\section{References}

Akmaev, R. A.: Simulation of large-scale dynamics in the mesosphere and lower thermosphere with the Doppler-spread parameterization of gravity waves 1 implementation and zonal mean climatologies, J. Geophys. Res., 106, 1193-1204, 2001.

Baldwin, M. P., Gray, L. J., Dunkerton, T. J., Hamilton, K., Haynes, P. H., Randel, W. J., Holton, J. R., Alexander, M. J., Hirota, I., Horinouchi, T., Jones, D. B. A., Kinnersley, J. S., Marquardt, C., Sato, K., and Takahashi, M.: The Quasi-biennial Oscillation, Rev. Geophys., 39, 179-229, 2001

Barath, F. T., Chavez, M. C., Cofield, R. E., Flower, D. A., Frerking, M. A., Gram, M. B., Harris, W. M., Holden, J. R., Jarnot, R. F., Kloezeman, W. G., Klose, G. J. Lau, G. K., Loo, M. S., Maddison, B. J., Mattauch, R. J., McKinney, R. P., Peckham, G. E., Pickett, H. M., Siebes, G., Soltis, F. S., Suttie, R. A. Tarsala, J. A., Waters, J. W., and Wilson, W. J.: The Upper Atmosphere Research Satellite Microwave Limb Sounder Instrument, J. Geophys. Res., 98, 10, 751-762, 1993.

Beig, G., Keckhut, P., Lowe, R.P., Roble, R. G., Mlynczak, M. G., Scheer, J., Fomichev, V. I., Offermann D., French, W. J. R., Shepherd, M. G., Semenov, A. I., Remsberg, E. E., She C. Y., Lubken, F. J., Bremer, J., Clemesha, B. R., Stegman, J., Sigernes, F., and Fadnavis, S.: REVIEW OF MESOSPHERIC TEMPERATURE TRENDS, Rev. Geophys., 41, 4/1015, doi:10.1029/2002RG000121, 2003.

Burrage, M. D., Vincent, R. A, Mayr, H. G., Skinner, W. R., Arnold, N. F., and Hays, P. B.: Long-term variability in the equatorial middle atmosphere zonal wind, J. Geophys. Res., 101, 12847 , doi:10.1029/96JD00575, 1996. 
Bloomfield, P.: Fourier Analysis of Time Series: An Introduction, John Wiley and Sons, 1976.

Dunkerton, T. J.: On the mean meridional mass motions of the stratosphere and mesosphere, J. Atmos. Sci., 35, 2325-2333, 1978.

Dunkerton, T. J.: On the role of the Kelvin wave in the westerly phase of the semiannual zonal wind oscillation, J. Atmos. Sci., 36, 32-41, 1979.

Dunkerton, T. J.: Theory of the mesopause semiannual oscillation, J. Atmos. Sci., 39, 2681-2690, 1982a.

Dunkerton, T. J.: Wave transcience in a compressible atmosphere. 3 , The saturation of internal gravity waves in the mesosphere, J. Atmos. Sci., 39, 1042-1051, 1982b.

Dunkerton, T. J.: Stochastic parameterization of gravity wave stresses, J. Atmos. Sci., 39, 1711-1725, 1982c.

Dunkerton, T. J.: A two-dimensional model of the quasi-biennial oscillation, J. Atmos. Sci., 42, 1151-1160, 1985a.

Dunkerton, T. J. and Delisi, D. P.: Climatology of the Equatorial Lower Stratosphere, J. Atmos. Sci., 42, 376-396, 1985b.

Dunkerton, T. J.: The role of gravity waves in the quasi-biennial oscillation, J. Geophys. Res., 102, 26 053-26 076, 1997a.

Dunkerton, T. J. and Delisi, D. P.: Interaction of the quasi-biennial oscillation and the stratopause semiannual oscillation, J. Geophys. Res., 102, 26 107-26 116, 1997b.

Fleming, E. L., Chandra, S., Barnett, J. J., and Corney, M.: Zonal Mean Temperature, Pressure, Zonal Wind and Geopotential Height as Functions of Latitude, Adv. Space Res., 10, 12, 11-59, 1990.

Fritts, D. C. and Lu, W.: Spectral estimates of gravity wave energyand momentum fluxes, II, Parameterization of wave forcingand variability, J. Atmos. Sci., 50, 3695-3713, 1993.

Garcia, R. R., Dunkerton, T. J., Lieberman, R. S., and Vincent, R. A.: Climatology of the semiannual oscillation of the tropical middle atmosphere, J. Geophys. Res., 102, 26019-26032, November 27, 1997.

Garcia, R. R. and Solomon, S.: The effect of breaking gravity waves on the dynamics and chemical composition of the mesosphere and lower thermosphere, J. Geophys. Res., 90, 3850-3868, 1985.

Geller, M. A.: Modeling the middle atmosphere circulation, Dynamics of the Middle Atmosphere, edited by: Holton, J. R. and Matsuno, D., 467-500, Terra pub. Tokyo, 1984.

Hamilton, K., Wilson, R. J., Mahlman, J. D., and Umscheid, L. J.: Climatology of the SKYHI troposphere-stratospheremesosphere general circulation model, J. Atmos. Sci., 52, 5-43, 1995.

Hamilton, K.: Dynamics of the stratospheric semi-annual oscillation, J. Meteorol. Soc. Jpn., 64, 227-244, 1986.

Haynes, P. H.: The latitudinal structure of the quasi-biennial oscillation, Q. J. R. Met. Soc., 124, 2645-2670, 1998.

Hays, P. B., Abreu, V. J., Dobbs, M. E., Gell, D. A., Grassl, H. J., and Skinner, W. B.: The High Resolution Doppler Imager on the Upper Atmosphere Research Satellite, J. Geophys. Res., 98, 10713-10723, 1993.

Hines, C. O.: Doppler-spread parameterization of gravity-wave momentum deposition in the middle atmosphere, 1, Basic formulation, J. Atmos. Solar Terr. Phys., 59, 371-386, 1997a.

Hines, C. O.: Doppler-spread parameterization of gravity-wave momentum deposition in the middle atmosphere, 2, Broad and quasi monochromatic spectra, and implementation, J. Atmos. Solar
Terr. Phys., 59, 387-400, 1997b.

Hirota, I.: Observational evidence of the semiannual oscillation in the tropical middle-atmosphere - a review, Pure Appl. Geophys., 118, 217-238, 1980.

Hitchman, M. H. and Leovy, C. B.: Evolution of the zonal mean state in the equatorial middle atmosphere during October 1978May 1979, J. Atmos. Sci., 43, 3159-3176, 1986.

Hitchman, M. H. and Leovy C. B.: Estimation of the Kelvin wave contribution to the semiannual oscillation, J. Atmos. Sci., 45, 1462-1475, 1988.

Holton, J.R., and Lindzen, R.: An updated theory for the quasibiennial cycle of the tropical stratosphere, J. Atmos. Sci., 29, 1076-1080, 1972.

Holton, J.R., and Tan, H.C.: The influence of the equatorial quasibiennial oscillation on the global circulation, at $50 \mathrm{mb}$, J. Atmos. Sci., 37, 2200-2208, 1980.

Huang, F. T. and Reber, C. A.: Seasonal behavior of the semidiurnal and diurnal tides, and mean flows at $95 \mathrm{~km}$, based on measurements from the High Resolution Doppler Imager (HRDI) on the Upper Atmosphere Research Satellite (UARS), J. Geophys. Res., 108(D12), 4360, doi:10.1029/2002JD003189, 2003.

Huang, F. T., Reber, C. A., Austin, J.: Ozone diurnal variations observed by UARS and their model simulation, J. Geophys. Res., 102, 12,971-12,985, 1997.

Huang, F. T. and Reber, C. A.: "Synoptic" estimates of chemically active species and other diurnally varying parameters in the stratosphere, derived from measurements from the Upper Atmosphere Research Satellite (UARS), J. Geophys. Res., 106, 16551667, 2001.

Huang, F. T. and Reber, C. A.: Nonmigrating semidiurnal and diurnal tides at $95 \mathrm{~km}$ based on wind measurements from the High Resolution Doppler Imager (HRDI) on UARS, J. Geophys. Res., 109, D10110, doi:10.1029/2003JD004442, 2004.

Huang, F. T., Mayr, H. G., and Reber, C. A.: Intra-seasonal Oscillations (ISO) of zonal-mean meridional winds and temperatures as measured by UARS, Ann. Geophys., 23, 1131-1137, 2005, http://www.ann-geophys.net/23/1131/2005/.

Huang, F. T., Mayr, H. G., Reber, C. A., Killeen, T., Russell, J., Mylnczak, M., Skinner, W., and Mengel, J.: Diurnal variations of temperature and winds inferred from TIMED and UARS measurements, J. Geophys. Res., in press, 2006.

Huesmann, A. and Hitchman, M. H.: The stratospheric quasibiennial oscillation in the NCEP reanalysis: Climatological structures, J. Geophys. Res., 106, 11 859-11 874, 2001.

Labitzke, K.: On the interannual variability of the middle stratosphere during northern winters, J. Meteorol. Soc. Jpn., 60, 124 139, 1982.

Labitzke, K.: Sunspots, the QBO and stratospheric temperature in the north polar region, Geophys. Res. Lett., 14, 535-537, 1987.

Labitzke, K. and Van Loon, H.: Association between the 11-year solar cycle, the QBO and the atmosphere. Part I: the troposphere and stratosphere in the northern hemisphere in winter, J. Atm. Terr. Phys., 50, 197-206, 1988.

Labitzke, K. and Van Loon, H.: On the association between the QBO and the extratropical stratosphere, J. Atm. Terr. Phys., 54, 1453-1463, 1992.

Leblanc, T., McDermid, I. S., Keckhut, P., Hauchecorne, A., She, C. Y., and Kruger, D. A.: Temperature climatology of the middle atmosphere from long-term lidar measurements at middle and 
low latitudes, J. Geophys. Res., 103, 17 191-17 204, July, 1998.

Leblanc, T. and McDermid, I. S.: Quasi-biennial oscillation signatures in ozone and temperature observed by lidar at Mauna Lao, Hawaii $\left(19.5^{\circ} \mathrm{N}, 155.6^{\circ} \mathrm{W}\right)$, J. Geophys. Res., 106, 14869 14 874, 2001.

Lindzen, R. S. and Holton, J. R.: A theory of the quasi-biennial oscillation, J. Atmos. Sci., 25, 1095-1107, 1968.

Lindzen R. S.: Turbulence and stress due to gravity wave and tidal breakdown, J. Geophys., Res., 86, 9707-9714, 1981

Meyer, W. D.: A diagnostic numerical study of the semiannual variation of the zonal wind in the tropical stratosphere and mesosphere, J. Atmos. Sci., 27, 820-830, 1970.

Manzini, E., McFarlane, N. A., and McLandress, C.: Impact of the Doppler spread parameterization in the simulation of the middle atmosphere circulation using the MA/ECHAM4 general circulation model, J. Geophy. Res., 102, 25 751-25 762, 1997.

Mayr, H. G., Mengel, J. G., Hines, C. O., Chan, K. L., Arnold, N. F., Reddy, C. A., and Porter, H. S.: The gravity wave Doppler spread theory applied in a numerical spectral model of the middle atmosphere 2. Equatorial oscillations, J. Geophy. Res., 102, 26093-26 105, 1997.

Mayr, H. G., Mengel, J. G., Reddy, C. A., Chan, K. L., and Porter, H. S.: The role of gravity waves in maintaining the QBO and SAO at equatorial latitudes, Adv. Space Res., 24, 1531-1540, 1999.

Mayr, H. G., Mengel, J. G., Reddy, C. A., Chan, K. L., and Porter, H. S.: Properties of QBO and SAO generated by gravity waves, J. Atmos. Solar-Terr. Phys., 62, 1135-1154, 2000.

Mayr, H. G, and Mengel, J. G.: Inter-annual variations of the diurnal tide in the mesosphere generated by the quasi-biennial oscillation, J. Geophys. Res., 110, D10111, doi:10.1029/2004JD005055, 2005.

McLandress, C.: On the importance of gravity waves in the middle atmosphere and their parameterization in general circulation models, J. Atmos. Solar-Terr., 60, 1357-1383, 1998.

McLandress, C.: Inter-annual variations of the diurnal tide in the mesosphere induced by a zonal-mean wind oscillation in the tropics, Geophys. Res. Lett., 29, 9, 1305, doi:10.1029/2001GL014551, 2002.

Mengel, J. G., Mayr, H. G., Chan, K. L., Hines, C. O., Reddy, C. A., Arnold, N. F., and Porter, H. S.: Equatorial oscillations in the middle atmosphere generated by small scale gravity waves, Geophys. Res. Lett., 22, 3027-3030, 1995.
Pawson, S and Fiorino, M.: A comparison of reanalyses in the tropical stratosphere, Part 2: the quasi-biennial oscillation, Climate Dyn., 14, 645-658, 1998.

Plumb, R. A.: The interaction of two internal waves with the mean flow: Implications for the theory of the quasi-biennial oscillation, J. Atmos. Sci., 34, 1847-1858, 1977.

Plumb, R. A. and Bell, R. C.: A model of the quasi-biennial oscillation on an equatorial beta-plane, Q. J. R. Meteorol. Soc., 108, 335-352, 1982.

Randel, W. J., Wu, F., Swinbank, R., Nash, J., and O'Neill, A.: Global QBO Circulation Derived from UKMO Stratospheric Analysis, J. Atmos. Sci., 56(4), 457-474, 1999.

Reber, C. A.: The Upper Atmosphere Research Satellite (UARS), Geophys. Res. Lett., 20(12), 1215-1218, 1993.

Reed, R. J.: The quasi-biennial oscillation of the atmosphere between 30 and $50 \mathrm{~km}$ over Ascension Island, J. Atmos. Sci., 22, 331-333, 1965.

Reed, R. J.: Zonal wind behavior in the equatorial stratosphere and lower mesosphere, J. Geophys. Res., 71, 4223-4233, 1966.

Reed, R. J.: W. J. Campbell, L. A. Rasmussen, and Rogers, D. G.: Evidence of a downward propagating annual wind reversal in the equatorial stratosphere, J. Geophys. Res., 66, 813-818, 1961.

Remsberg, E. E., Bhatt, P. P., and Deaver, L. E.: Seasonal and longer-term variations in middle atmosphere temperature from HALOE on UARS, J. Geophys. Res., 107, D19, 4411, doi:10.1029/2001JD001366, 2002.

Russell, III J. M., Mlynczak, M. G., Gordley, L. L., Tansock, J., and Esplin, R.: An overview of the SABER experiment and preliminary calibration results, Proceedings of the SPIE, 44th Annual Meeting, Denver, Colorado, July 18-23, 3756, 277-288, 1999.

Shepherd, M. G., Evans, W. F. J., Hernandez, G., Offermann, D., and Takahashi, H.: Global variability of mesospheric temperature: Mean temperature field, J. Geophys. Res., 109, D24117, doi:10.1029/2004JD005054, 2004

Strobel, D. F.: Parameterization of atmospheric heating rate from 15 to $120 \mathrm{~km}$ due to $\mathrm{O}_{2}$ and $\mathrm{O}_{3}$ absorption of solar radiation, $\mathrm{J}$. Geophys. Res., 83, 6225-6230, 1978.

Takahashi, M.: Simulation of the quasi-biennial oscillation in a general circulation model, Geophys. Res. Lett., 26 , 1307-1310, 19999.

Zhu, X.: Radiative cooling calculated by random band models with S-1-beta tailed distribution, J. Atmos., Sci., 46, 511-520, 1989. 